\title{
A Theoretical Investigation of Decorated Novel Triazoles as DSSCs in PV Devices
}

Louis-Charl Cloete Coetzee ( $\square$ Louischarlc0@gmail.com )

University of Johannesburg https://orcid.org/0000-0003-3003-3025

Adedapo Adeyinka

University of Johannesburg Faculty of Science

Nomampondo Magwa

University of South Africa - Florida Campus: University of South Africa - Science Campus

\section{Research Article}

Keywords: DFT, TD-DFT, DSSCs, Donor, $\pi$-spacer, acceptor

Posted Date: August 9th, 2021

DOl: https://doi.org/10.21203/rs.3.rs-758446/v1

License: (1) This work is licensed under a Creative Commons Attribution 4.0 International License.

Read Full License

Version of Record: A version of this preprint was published at Journal of Molecular Modeling on November 15th, 2021. See the published version at https://doi.org/10.1007/s00894-021-04975-y. 


\title{
A theoretical investigation of decorated novel triazoles as DSSCs in PV devices
}

\section{Louis-Charl Coetzee ${ }^{\mathrm{a}}$, Adedapo Adeyinka ${ }^{\mathrm{a}}$, Nomampondo Magwa ${ }^{\mathrm{b}}$,}

${ }^{a}$ Research Centre for Synthesis and Catalysis, Department of Chemical Sciences, University of Johannesburg, PO Box 524, Auckland Park, Johannesburg, 2006, Gauteng, South Africa.

Tel.: +27604699790

${ }^{b}$ Department of Chemistry, University of South Africa, Private Bag X6, Florida, Roodepoort, Johannesburg, 1710, Gauteng, South Africa.

Tel.: +27(011)6709302

Louis-Charl Coetzee

Louischarlc0@gmail.com

\begin{abstract}
Some novel metal-free 1,2,4-triazole compounds A1-A8, based on the 3,5-bis(2-hydroxyphenyl)-1,2,4triazole derivatives were examined for Photovoltaic properties using density functional theory (DFT) and time dependent density functional theory (TD-DFT) calculations for the use of dye sensitized solar cells (DSSCs). Through deductive logic, the fluorescence emission $\left(\Phi_{f}\right)$ and charge collection $\left(\eta_{c}\right)$ efficiencies of these compounds as dyes were obtained and used to determine each dye's incident conversion efficiency (IPCE). Furthermore, these parameters were also employed to assess the dye's potential for photovoltaic technology. However, this technique is more suitable to predict the suitability of the dye for photovoltaic applications, and cannot measure the efficiency of DSSCs
\end{abstract}

Keywords DFT, TD-DFT, DSSCs, Donor, $\pi$-spacer, acceptor

\section{Introduction}

The rise in energy demands and the fear of global warming have led to a shift away from fossil fuels in recent years [1]. Renewable energy sources are an attractive alternative since they are naturally replenished in a continuous manner. As they do not emit $\mathrm{CO}_{2}$ and other harmful gases into the atmosphere, they can be referred to as green or clean energy [2]. Photovoltaic (PV) systems that produce energy from solar radiation has become a popular renewable energy source in recent times. This technology relies entirely on the photoelectric effect. Silicon is mostly used in PV systems due to its hole transporting and charge carrier mobility [3]. Since the process of fabricating silicon solar cells is not easy and require a high cost, it is challenging to distribute PV systems. The low cost, facile fabrication, and high-power conversion efficiency of Dye Sensitized Solar Cells (DSSCs) makes them suitable candidates to replace silicon in PV systems. Moreover, these cells can also function in low light conditions [4]. For a long time, Ru-based complexes held the record for the highest efficiency in DSSCs of over $11 \%$. However, their high cost, nonrenewability and difficulty in purification made them unsuitable for commercial usage. Seeking more worthwhile dyes, researchers stumble across zinc porphyrin complexes in 2014 with an efficiency of $13.00 \%$. Soon afterwards, a DSSC with two cosensitized metal-free organic dyes achieved a higher efficiency of $14.30 \%$ in 2015 [5]. Thus, it is more suitable to use organic dyes not only because of this 
efficiency, but also due to their lower cost and simple synthetic procedures. Other advantages that they offer are high molar absorption coefficients and variable structure adjustibilities [6,7]. A DSSC usually consist of a material that is chemisorbed onto a mesoporous material, which is usually titanium dioxide $\left(\mathrm{TiO}_{2}\right)$. An organic dye is usually divided into donor-linker-acceptor (D- $\pi$-A) fragments where intramolecular charge transfer (ICT) occurs from D to A via the $\pi$-spacer [8-11] (Figure 1). The $\pi$-spacer units improve the conjugation and enhances the stability of the resulting photosensitizers [12]. Moreover, they offer a high degree of electron delocalization that allows for substantial electronic communication between individual $\pi$-spacer units. This allows them to mediate charge/energy over long distances [13]. Triaryl amine, starburst, carbazoles, indoles, phenoxides, phenothiazine and coumarines are commonly used as donor groups [11-18], while commonly used $\pi$-spacer units are vinylene and thiophene groups [16,18], and commonly used as acceptor groups are cyanoacetic acid, rhodamine-3-acetic acid, barbituric acid, hydroxyl, phosphoric acid, cyanoacrylic acid and carboxylic acid $[16,19,20]$. Smooth electron movements between $\mathrm{D}$ and the $\pi$-spacer groups can be achieved for small dihedral angles between the former and the latter. The $\pi$-electrons can then be effectively delocalized onto $\mathrm{A}$ if it is approximately co-planar to the $\pi$-spacer. This then causes excitation onto $\mathrm{A}$, which is subsequently injected into the conduction band edge of $\mathrm{TiO}_{2}$. Once injected, $\pi$ electrons are then transferred onto a thin layer transparent conducting oxide (TCO) electrode, which is usually tin dioxide $\left(\mathrm{SnO}_{2}\right)$ that acts as an anode. A current can then be obtained by connecting an external circuit between the anode and a counter electrode. The latter is usually indium dioxide $\left(\mathrm{InO}_{2}\right)$. The electrons can then be regenerated back into the dye via an electrolyte (usually the $I^{-} / I_{3}^{-}$ redox couple) [18]. However, it is essential that A and D should be non-planar, otherwise dye aggregation can occur due to intermolecular interactions, which results in dimers that suppresses electron injection into the conduction band edge of $\mathrm{TiO}_{2}$. The introduction of an anti-aggregating agent such as chenodeoxy cholic acid (CDCA), which can be used with organic dyes can reduce dye aggregation by enhancing electron transport, which leads to larger power conversion efficiencies [21]. For a high absorption coefficient, $\mathrm{D}$ and the $\pi$-spacer must also be non-planar [22,23]. Efficiencies are reduced when light generated current encounters a hole that allows them to recombine and emit a photon. Recombination can also occur when chargecarriers encounter a defect in the crystal structure of the solar cell. Both processes cancel out their input into the electric current [3]. To maximize efficiencies, the dye must be luminescent, absorb in the visible and near-infrared (NIR) regions, its lowest unoccupied molecular orbital (LUMO), must lie above the conduction band edge of $\mathrm{TiO}_{2}$, its highest occupied molecular orbital (HOMO) must lie below the HOMO of the redox electrolyte, it should have a low energy gap between HOMO and LUMO, a high interfacial dipole moment and the periphery of the dye should be hydrophobic $[18,24,25]$.

There is still an ongoing search for dye materials with higher efficiency which can be incorporated into DSSCs [18]. Hence, this study focuses on a theoretical evaluation of 3,5-bis(2-hydroxyphenyl)1,2,4-triazole derivatives as potential DSSC agents using DFT and TD-DFT methods (Figure 2, where hydrogen atoms were omitted for clarity). Our interest in this compound lies in its aromatic groups that contains active sites to build-in various $D-\pi-A$ moieties. Therefore, we decorated this compound further with starburst donor groups, thiophene $\pi$ spacer groups and cyanoacrylic acid acceptor groups 
(Figure 3) before carrying out a theoretical evaluation of their suitability as dyes in DSSCs. Although triazoles have shown that they can be used as conjugative $\pi$-spacers in intramolecular electron transfer processes [26], to the best of our knowledge 1,2,4-triazoles has only been used as electron acceptor units in organic light emitting diodes [2730]. Since several $\pi$-spacer units that contains electron-deficient moieties have been reported, some which have produced efficiencies of $8.70 \%$ [5], it was worthwhile to assess electron-deficient 1,2,4-triazole as a $\pi$-spacer unit. Herein, we report the structures of various 3,5-bis(2-hydroxyphenyl)1,2,4-triazole derivatives (Figure 4) and their potential abilities as DSSCs.

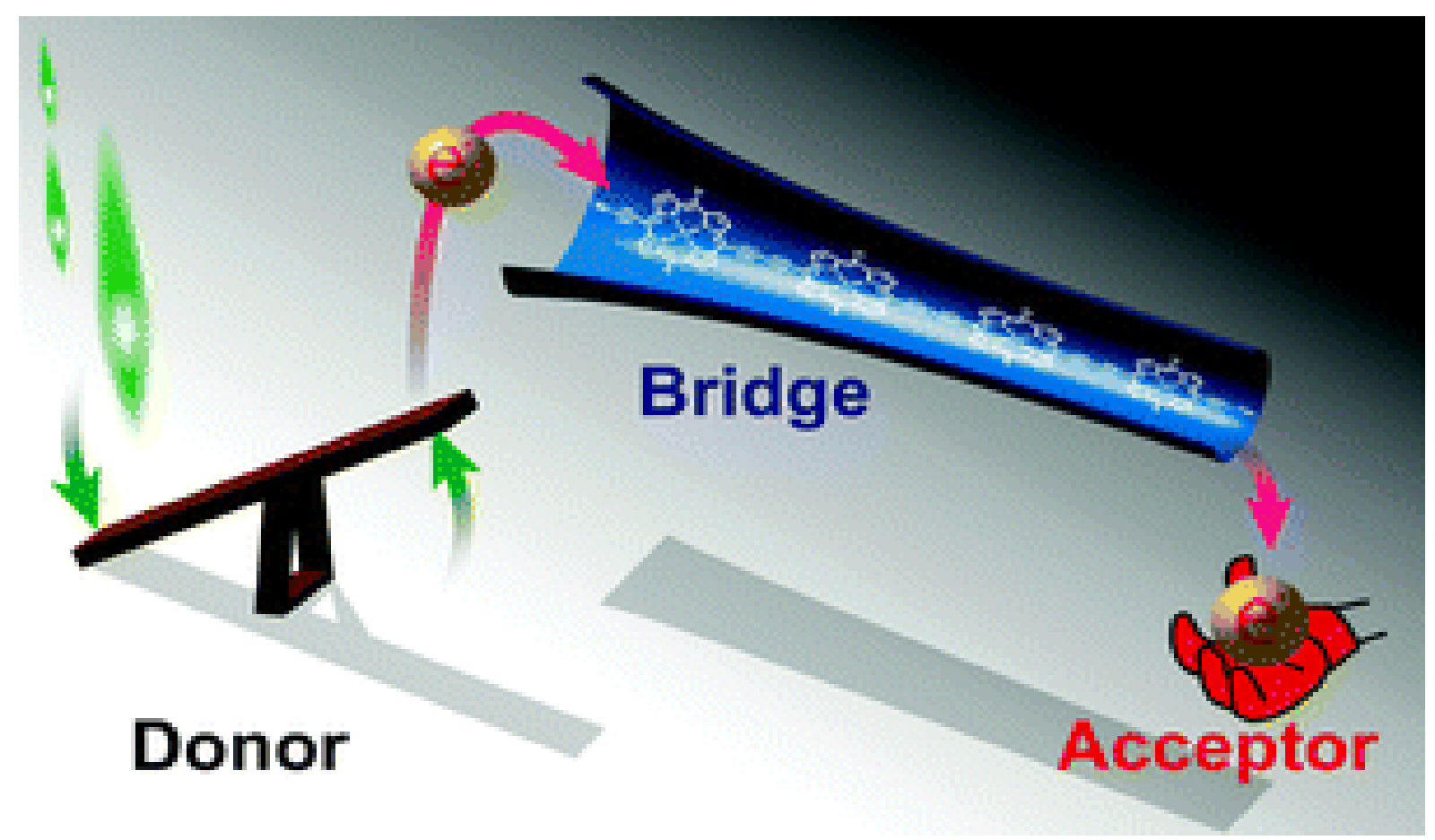

Figure 1. Pictorial diagram of the donor, $\pi$-spacer, and acceptor system [13]

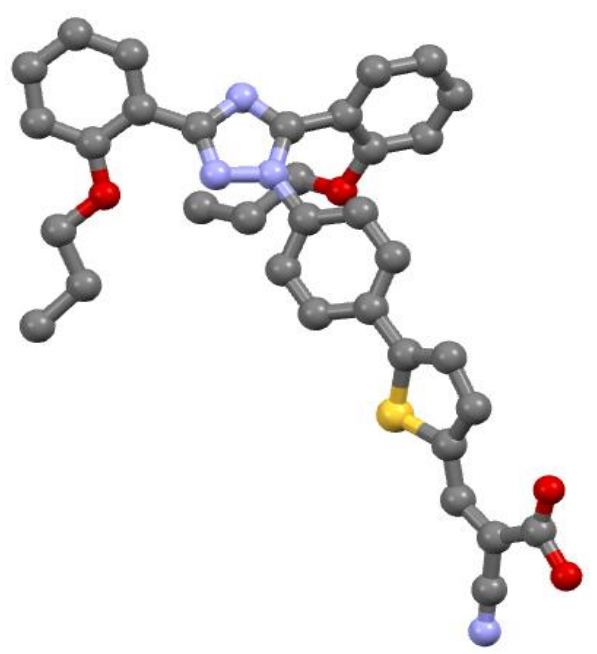

A1

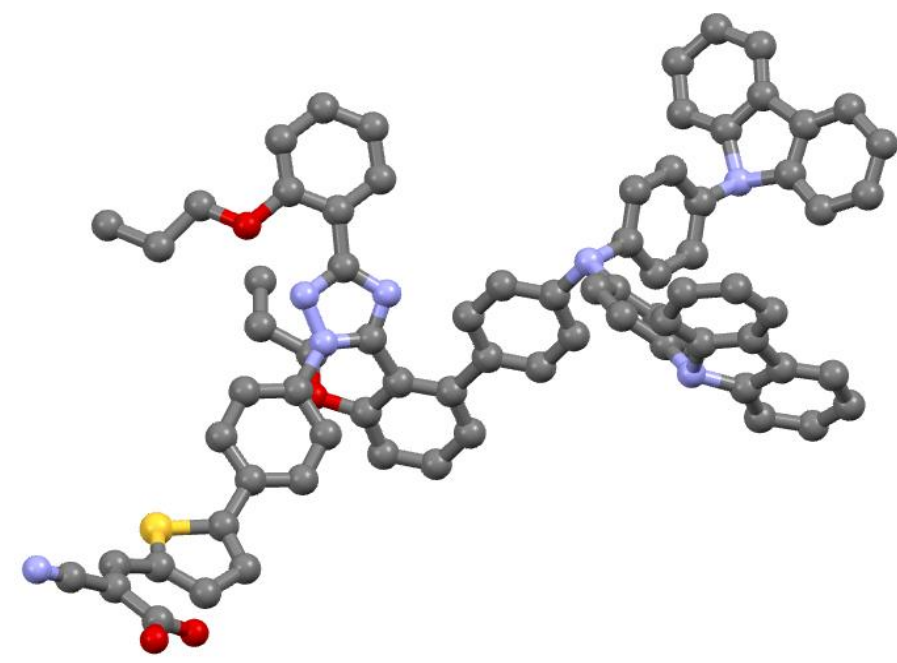

A2 


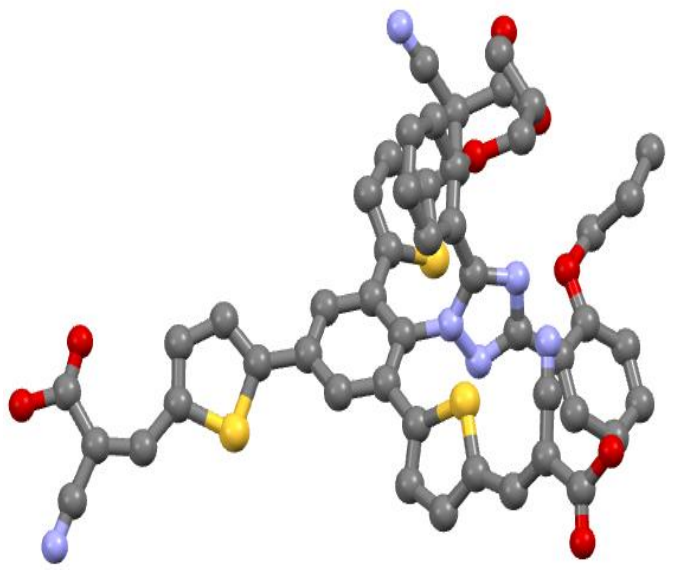

A3

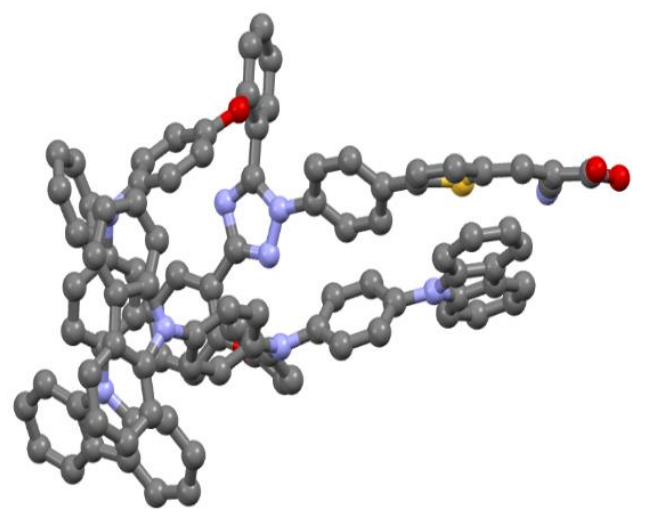

A5

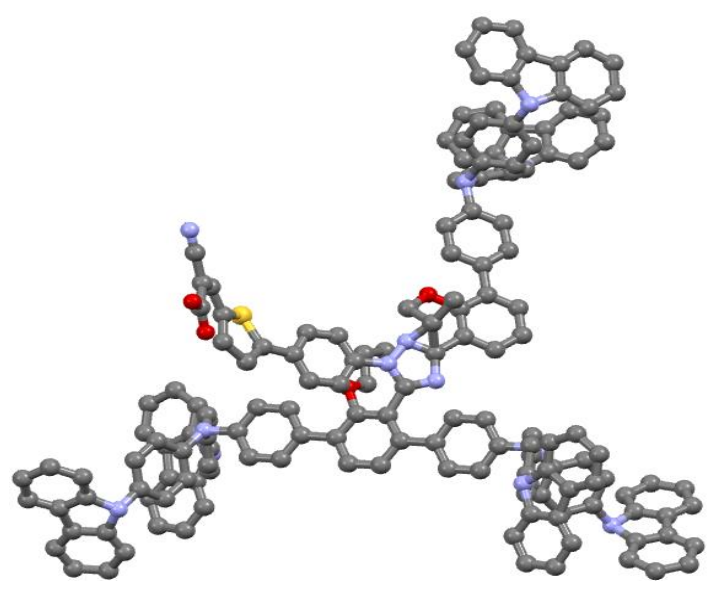

A7

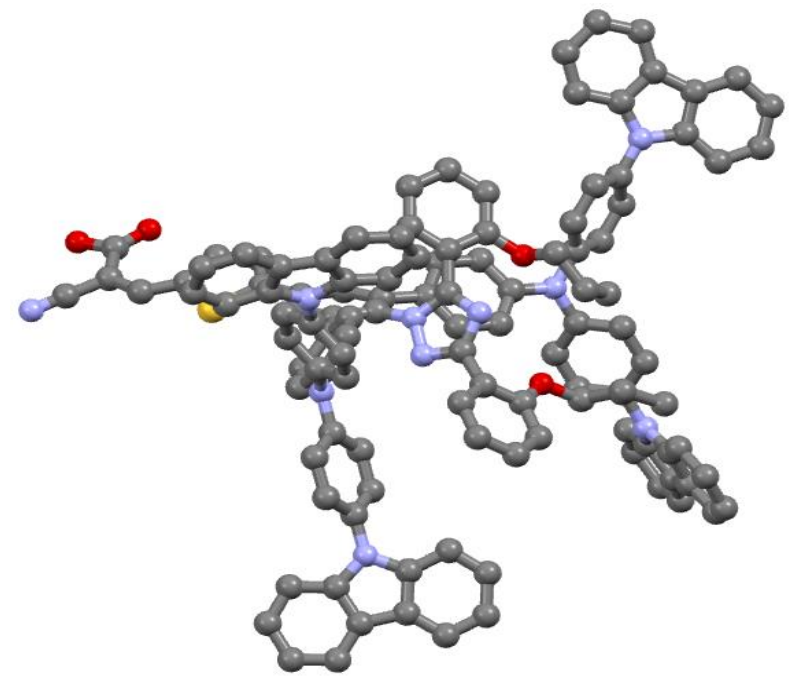

A4

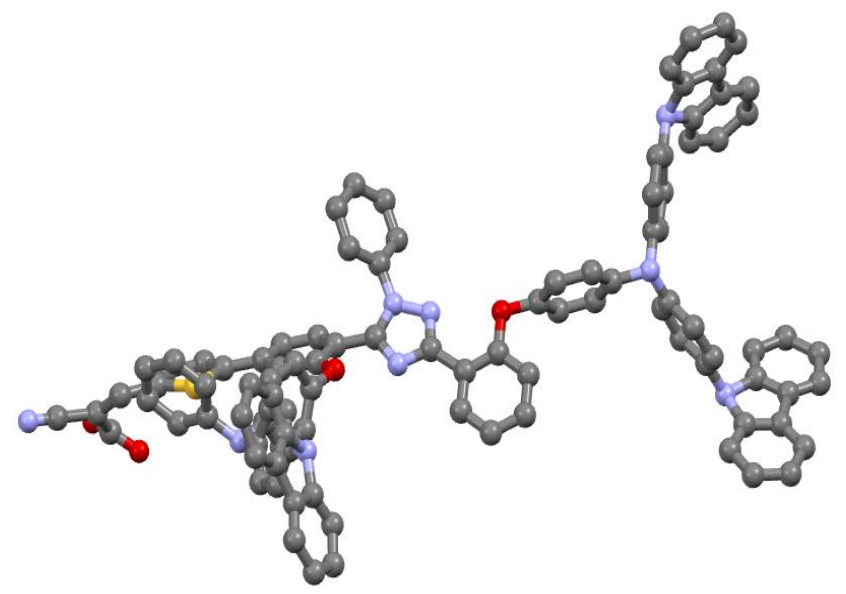

A6

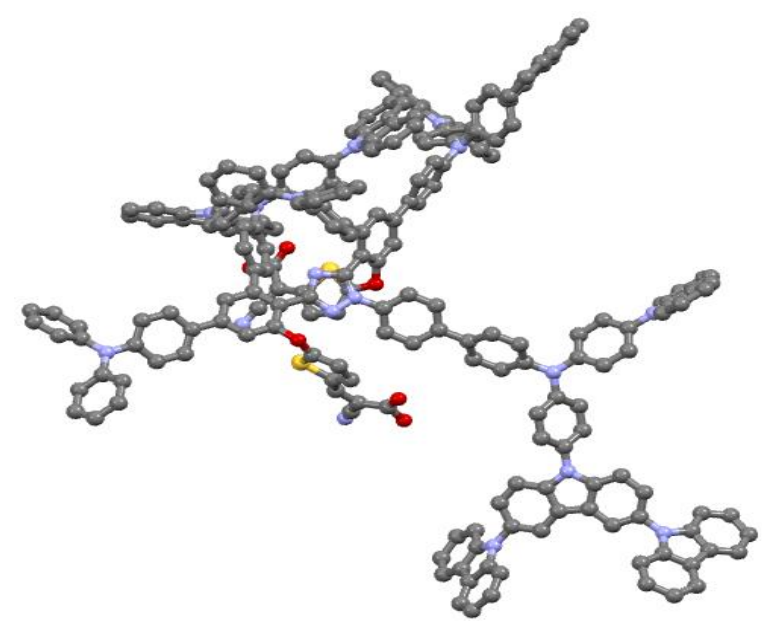

A8

Figure 2. Structures for 3,5-bis(2-hydroxyphenyl)-1,2,4-triazole derivatives obtained through Mercury 2020.3.0 

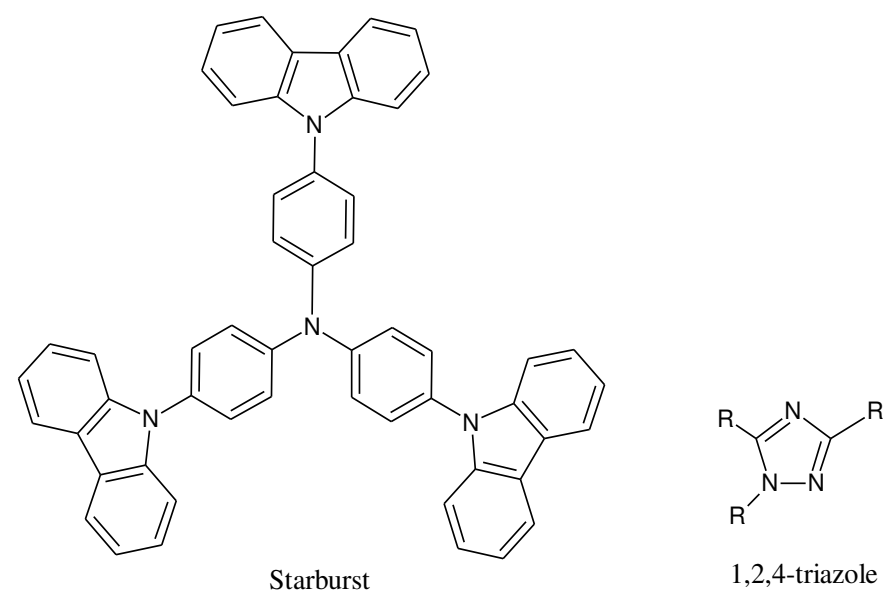

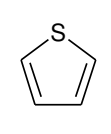

thiophene

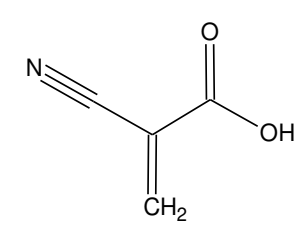

cyano acrylic acid

Figure 3. Donor, $\pi$-spacer and acceptor groups that were selected for this study

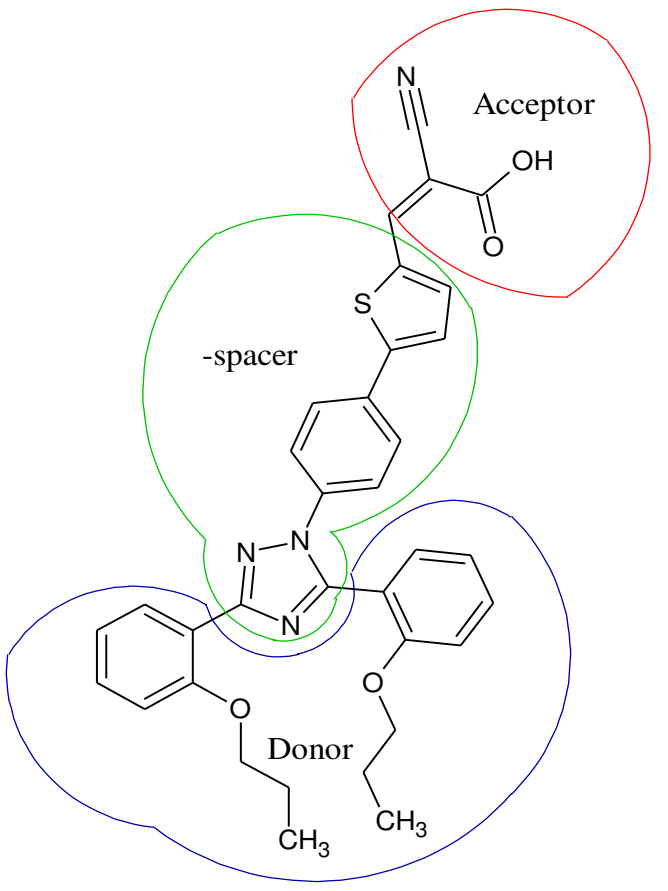

A1

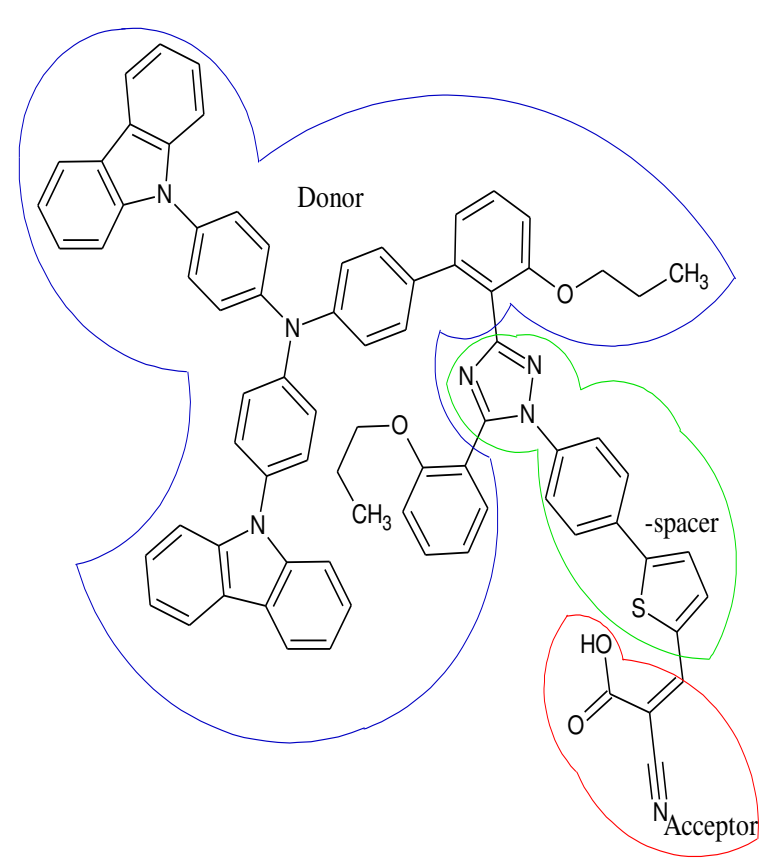

A2 

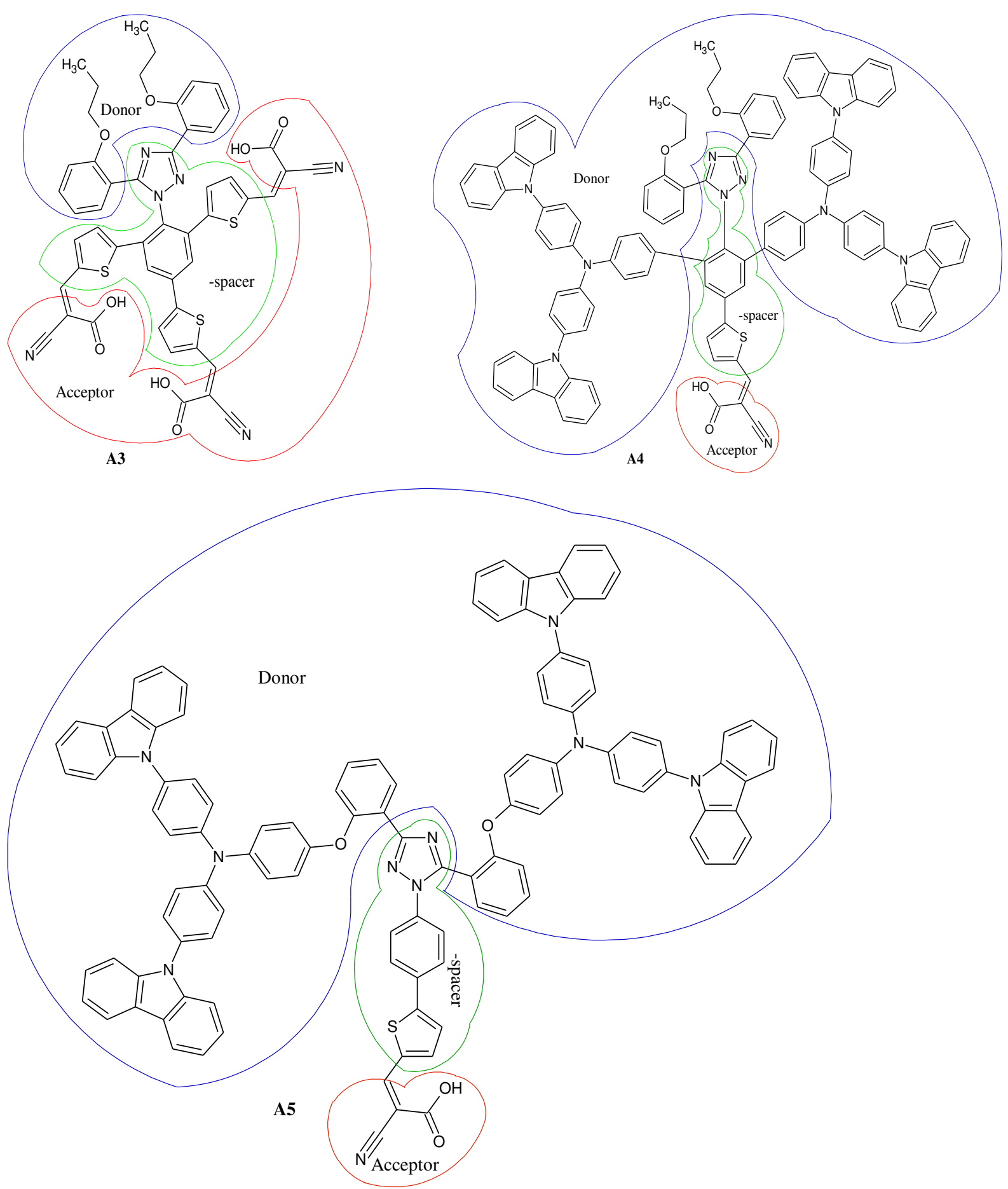


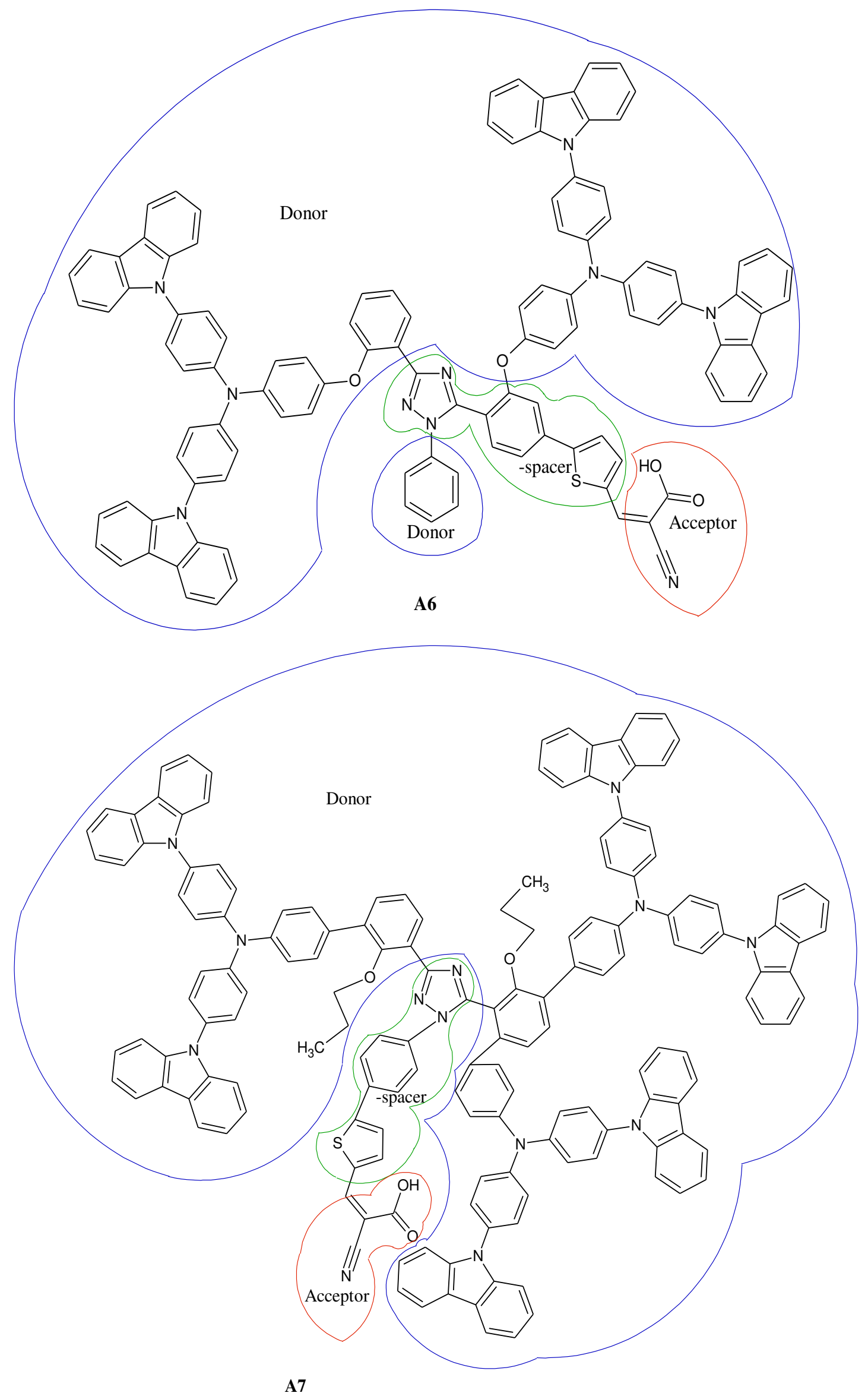




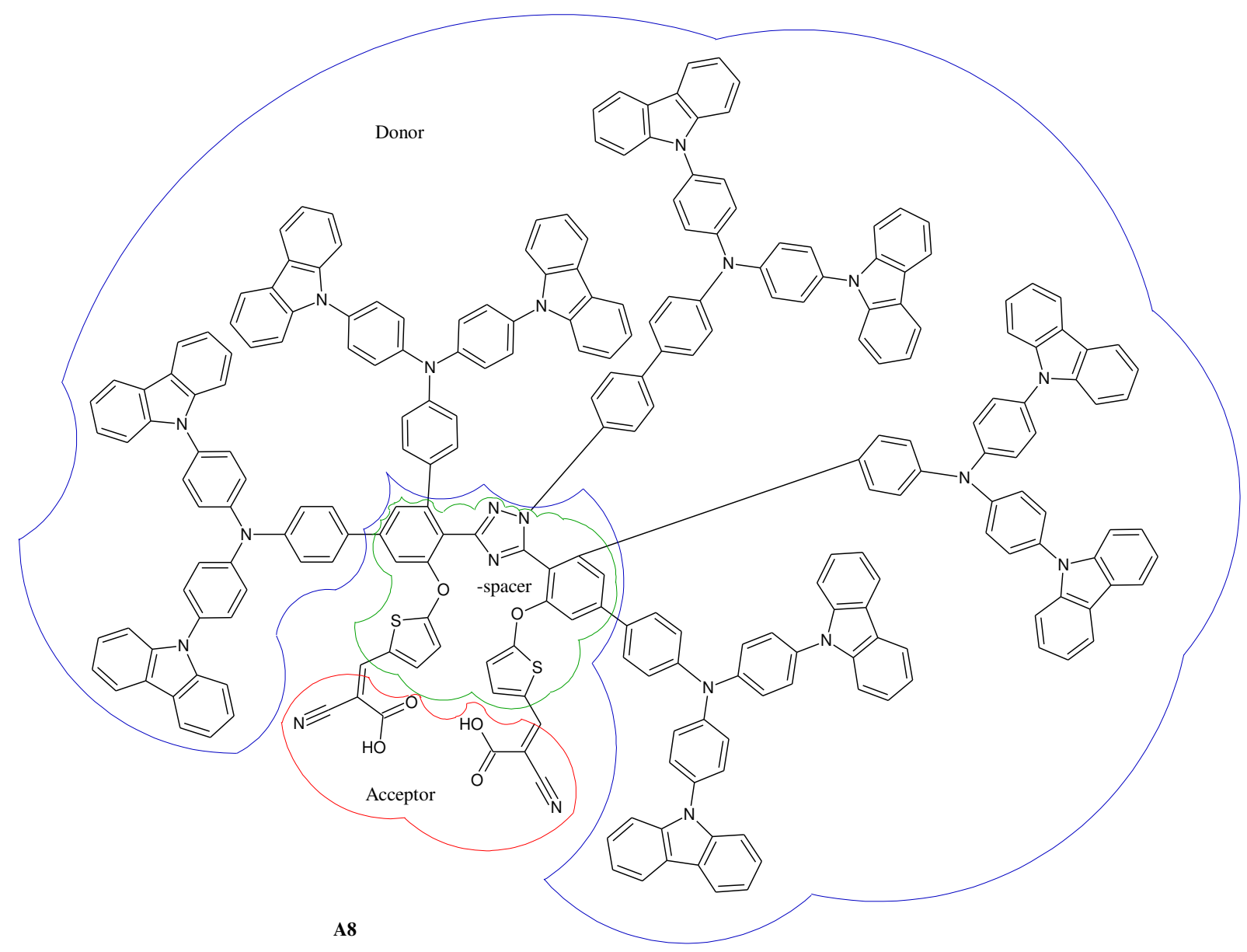

Figure 4. Structures of 3,5-bis(2-hydroxyphenyl)-1,2,4-triazole derivatives used in TD-DFT studies

\section{Methodology}

\subsection{Computational details}

All calculations were carried out with Gaussian 09 rev E01 software [31]. The geometries of all molecules were optimized in the gas phase for both DFT and TD-DFT calculations. All structures were optimized at the M06-2x/6-31G(d,p) level of theory. The optimization process was carried out in conjunction with frequency calculations to verify that structures obtained were of minimum energy. Using their optimized structures as input, we carried out TD-DFT calculations on the organic dyes labelled as A1-A8 (Figure 3 ) in the gas phase and their frontier molecular orbital natures (FMO) were analyzed using multiwfn software [31] by dividing their structures into D- $\pi-A$ fragments (Figure 4) to study their ICT at the same level of theory. In addition, molecular orbital structures as well as energies of their HOMO and
LUMO were also obtained from an analysis of the optimized structures.

\subsection{Methods of calculation}

The incident photon conversion efficiency (IPCE), charge collection efficiency $\left(\eta_{\mathrm{c}}\right)$, electron injection efficiency $\left(\Phi_{i n j}\right)$ and light harvesting efficiency (LHE) were shown to be related to Eqs. (1) and (2) [32]:

$\mathrm{IPCE}=\mathrm{LHE} \times \Phi_{i n j} \times \eta_{c}$

LHE $=1-10^{-f}$

where $f$ is the oscillator strength that corresponds to the maximum absorption wavelength $\left(\lambda_{\max }\right)$ in the visible and NIR region.

The electron injection free energy $\left(\Delta G_{i n j}\right)$ can be obtained through Eq. (3) [33] 
$\Delta G_{i n j}=E_{o x}^{d y e^{*}}-E_{C B}$

where $E_{o x}^{d y e^{*}}$ and $E_{C B}$ are the dye's excited state oxidation potential and the ground state reduction potential of $\mathrm{TiO}_{2}$, respectively. The literature value of $E_{C B}$ is $-4.21 \mathrm{eV}$ [34], while $E_{o x}^{d y e *}$ was calculated using Eq. (4) [33]

$E_{o x}^{d y e *}=E_{o x}^{d y e}-\Delta E$

Where $E_{o x}^{d y e}$ is the dye's ground state oxidation potential given by $E_{o x}^{d y e}=-H O M O$ [33] and $\Delta E$ is the absorption energy that corresponds to $\lambda_{\max }$ in the visible or NIR region.

Since energy from the excited dye $\left(d y e^{*}\right)$ is released through diffusion into the $\mathrm{TiO}_{2}$ conduction band, a diffusion coefficient $D_{\pi}$ can be defined and is calculated using Stoke's equation [33]

$D_{\pi}=\frac{K_{B} T}{6 \pi \eta N_{A} r_{d y e}}$

where $K_{B}=$ Boltzman's constant, $\eta=$ the viscosity of the medium which is assumed to be $\mathrm{He}$ at $300 \mathrm{~K}$ $\left(20.0 \times 10^{-6} \mathrm{Pas}\right)$ in this case since the investigations were performed in the gas phase, $N_{A}=$ Avogadro's number and $r_{d y e}=$ the molecular radii of the dye. The latter can be obtained from the following equation [33]

$r_{\text {dye }}=a=\sqrt[3]{\frac{3 M}{4 \pi \rho N A}}$

where $a=$ Onsager cavity radii, $M=$ the molecular weight of the dye and $\rho=$ the density of He gas $\left(9.00 \times 10^{-2} \mathrm{~kg} \cdot \mathrm{m}^{-3}\right)$ at STP [33]

\section{Results and Discussion}

\subsubsection{Optimized geometry and electronic properties}

The correctness of the optimized structure of a molecule will determine the accuracy of a predicted
If we assume that the electron injection efficiency $\left(\Phi_{i n j}\right)$ of the dye is equal to the fluorescence emission factor $\left(\Phi_{f}\right)$ then we can define the latter as

$\Phi_{f}=\frac{I \varepsilon_{e m}}{I \varepsilon_{a b s}}$

where $I \varepsilon_{e m}$ and $I \varepsilon_{a b s}$ are the integrated emission and absorption coefficients respectively which corresponds to the areas under the emission and absorption spectra. The former can be obtained through extrapolation of the absorption spectra [33]

The charge collection efficiency $\left(n_{c}\right)$ can then be obtained through the following equation [32]

$n_{c}=\frac{D_{\pi}}{\left(\delta_{p}\right)^{2}}$

where $\delta_{p}$ is the potential difference between the LUMO of the dye and the conduction band gap of $\mathrm{TiO}_{2}[24]$

A relationship between the open circuit voltage $\left(V_{O C}\right)$ and LUMO of the dye also exist and is given in Eq. (9) [23]

$V_{O C}=E_{L U M O}-E_{C B}$

An important parameter to consider is the driving force for charge recombination $\Delta G_{r e c}^{0}$ which can be obtained through Eq. (10) [23]

$\Delta G_{\text {rec }}^{0}=E_{C B e}-E_{H O M O}$

Where $E_{C B e}$ is the redox potential of the electrolyte $I^{-} / I_{3}^{-}(-4.6 \mathrm{eV})$ and $E_{\text {Номо }}$ the redox potential of the dye in its ground state [23].

property. Optimization of each structure required a series of optimization steps before reaching its minimum energy configuration (Figure S1)conventionally known as the optimized structure. Frequency calculations were performed to validate 
the optimized structures as minima or transition state structures. Theoretically, any structure that has one imaginary frequency (i.e. negative vibrational frequency) is designated as a transition state, while those with two or more imaginary frequencies are higher order saddle point. Hence, it is generally accepted that a minimum energy structure should have no negative frequency. However, in the case of very large floppy molecules, negative vibrational frequencies within the range of $10-100 \mathrm{~cm}^{-1}$ can be ignored [36]. Since the molecules under investigation shows negligible stretches for negative vibrational frequencies, they can all be considered as stable structures for the purpose of the study. Figure 5 shows the parent compound on which all the dyes were constructed. A comparison between the IR stretches of the $\mathrm{C}=\mathrm{N}$ and $\mathrm{N}-\mathrm{N}$ moieties of the parent compound, and the dyes are displayed in Table 1. Significant $\mathrm{C}=\mathrm{N}$ up-field shifts are displayed in $\mathbf{A 4}$, A6 and A7. This could be because these molecules contain more than one donor group and only one acceptor group as opposed to the other molecules. The calculated IR stretches for the C-S-C, N-N, $\mathrm{C}=\mathrm{N}, \mathrm{COOH}$ and $\mathrm{C} \equiv \mathrm{N}$ moieties of all molecules are displayed in Table 2. In this case, $\mathbf{A 1}$ can be considered as the parent compound since it does not contain a starburst donor group. It is clear from the table that downfield shifts are observed for all the moieties. These shifts might arise due to the influence of the starburst moiety or in the case of $\mathbf{A 3}$, more than one acrylic acid acceptor moiety.

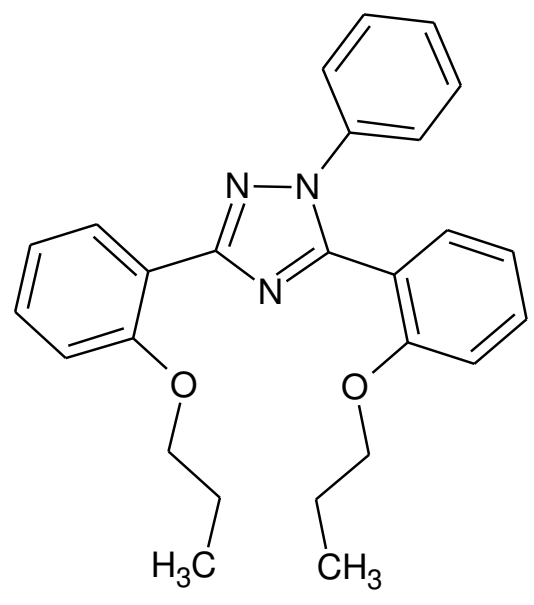

Figure 5. Parent compound of all the potential dyes

Table 1. $\mathrm{C}=\mathrm{N}$ and $\mathrm{N}-\mathrm{N}$ IR stretches of parent compound vs dyes

\begin{tabular}{|c|c|c|}
\hline & $\underline{\mathrm{IR}} \quad(\mathrm{C}=\mathrm{N})$ & $\underline{\mathrm{IR}}$ \\
\hline & $\left(\mathrm{cm}^{-1}\right)$ & $\left(\mathrm{cm}^{-1}\right)$ \\
\hline $\begin{array}{l}\text { Parent } \\
\text { compound }\end{array}$ & 1408 & 1248 \\
\hline A1 & 1408 & 1246 \\
\hline A2 & 1408 & 1273 \\
\hline A3 & 1363 & 1282 \\
\hline A4 & 1363 & 1282 \\
\hline A5 & 1399 & 1273 \\
\hline A6 & 1363 & 1282 \\
\hline A7 & 1372 & 1273 \\
\hline A8 & 1417 & 1273 \\
\hline
\end{tabular}

Table 2. $\mathrm{C} \equiv \mathrm{N}, \mathrm{COOH}$ and $\mathrm{C}-\mathrm{S}-\mathrm{C}$ IR stretches of the dyes

$\begin{array}{llll} & \underline{\mathrm{IR}(\mathrm{C} \equiv \mathrm{N})} & \underline{\mathrm{IR}(\mathrm{COOH})} & \underline{\operatorname{IR}(\mathrm{C}-\mathrm{S}-\mathrm{C})} \\ & \underline{\left(\mathrm{cm}^{-1}\right)} & \underline{\left(\mathrm{cm}^{-1}\right)} & \underline{\left(\mathrm{cm}^{-1}\right)} \\ \text { A1 } & 2389 & 1822 & 769 \\ \text { A2 } & 2416 & 1876 & 800 \\ \text { A3 } & 2416 & 1858 & 778 \\ \text { A4 } & 2416 & 1885 & 796 \\ \text { A5 } & 2407 & 1876 & 778 \\ \text { A6 } & 2416 & 1858 & 778 \\ \text { A7 } & 2416 & 1876 & 778 \\ \text { A8 } & 2416 & 1849 & 778\end{array}$


Figure 6 shows a graphical representation of the absorption spectra of these compounds that were investigated for potential DSSCs. These spectra were obtained from optimized ground state structures via TD-DFT calculations. To be able to rationalize the transition strengths, the absorption wavelengths $\left(\lambda_{\max }\right)$ were presented against both the absorptivity coefficients $(\varepsilon)$ and oscillator strengths $(f)$. A true picture is revealed by the observation of the transition probability per molecule from $f$, as against $\varepsilon$. The latter depends on the molecule's molecular weight [32]. The large $f$ in $\mathbf{A 1}$ and $\mathbf{A 2}$ is an indication of their strong transition intensities in comparison to the other molecules. These molecules also have high $\varepsilon$, which induces large LHEs (Table $3)$. The molecules' $\lambda_{\max }$ and $\varepsilon$ also reflect on the energy of the absorbed incident photon and the intensity of the absorption, except that the $\varepsilon$ considers the molecular weight, while $f$ does not [32]. This could be a possible reason why $f$ $(\mathrm{A} 2>\mathrm{A} 1>\mathrm{A6}>\mathrm{A} 5>\mathrm{A} 7>\mathrm{A} 8>\mathrm{A} 4>\mathrm{A3})$ and $\varepsilon$ $(\mathrm{A2}>\mathrm{A1}>\mathrm{A5}>\mathrm{A6}>\mathrm{A4}>\mathrm{A} 7>\mathrm{A8}>\mathrm{A3})$ shows different trends, which was observed by Sanusi et al [32] as well. The low $\varepsilon$ of $\mathbf{A 3}$ makes it highly unfavorable to be considered as a DSSC. Although $\mathbf{A 8}$ has a high interfacial dipole moment $(\mu)$, it also has a low $\varepsilon$. Thus, from the series, A1, A2, A6 and A7 might fulfill the entry requirements for potential DSSCs. However, a more thorough analyses have been performed on all these compounds to evaluate their effectiveness as potential DSSCs as well as to find out possible reasons why some are unsuitable candidates.

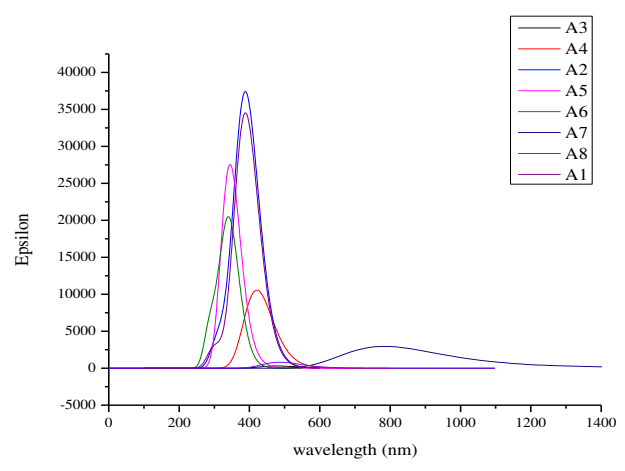

Figure 6. TD-DFT obtained UV-Vis absorption spectra of 3,5-bis(2-hydroxyphenyl)-1,2,4-triazole derivatives

Table 3. Molar absorption coefficients at maximum wavelengths and magnetic moments obtained through TD-DFT and DFT calculations

$\begin{array}{llllll} & f & \underline{\mathrm{LHE}} & \underline{\underline{\lambda_{\max }}} & \underline{\underline{\varepsilon_{A b s}}} & \underline{\mu} \\ & & & \underline{(\mathrm{nm})} & \underline{\left({\left.\mathrm{L} . \mathrm{mol}^{-1} \cdot \mathrm{cm}^{-1}\right)}\right.} & \underline{(\text { Debye })} \\ \mathbf{A 1} & 0.852 & 0.859 & 396.26 & 34486.64 & 5.75 \\ \text { A2 } & 0.900 & 0.874 & 389.70 & 37364.26 & 5.49 \\ \mathbf{A 3} & 0.007 & 0.017 & 478.29 & 299.28 & 5.71 \\ \text { A4 } & 0.008 & 0.018 & 474.14 & 10545.20 & 8.50 \\ \text { A5 } & 0.462 & 0.655 & 347.84 & 27524.13 & 5.08 \\ \text { A6 } & 0.490 & 0.677 & 341.83 & 20468.33 & 4.04 \\ \text { A7 } & 0.039 & 0.087 & 765.86 & 2951.84 & 6.79 \\ \text { A8 } & 0.019 & 0.043 & 483.46 & 810.14 & 12.94\end{array}$

The D- $\pi$-A moieties of most organic sensitizers results in rigid rod-shape configurations, which are adsorbed on the surface of spherical $\mathrm{TiO}_{2}$ particles, producing a radial arrangement where $\mathrm{A}$ with the anchoring segment point to the $\mathrm{TiO}_{2}$ surface and $\mathrm{D}$ away from the surface. These configurations are susceptible to aggregation for the strong dipoledipole interaction between the extended delocalized $\pi$-bonds. Self-quenching arises from close $\pi-\pi$ aggregation between molecules, resulting in reduction in electron injection into the conduction band edge of $\mathrm{TiO}_{2}$, and instability of the organic dye due to the formation of excited triplet states and unstable radicals under light irradiation. 
Aggregation can also aggravate charge recombination for the $I_{3}^{-}$and can easily penetrate through the big interspaces between chromophores. The addition of long alkyl chains on the $\pi$-conjugate segment of the rod-shape dyes can reduce charge recombination, which enhances input current. Transforming the rod-shape dye into a starburst type by employing the starburst triarylamine units as a donor segment can also reduce charge recombination. The enhancement of the latter can be ascribed to the aggregation-resistant nonplanar starburst configuration and multiphenyl units on the starburst triarylamine, which to some degree can block the approach of the $I_{3}^{-}$. This however does not eliminate the aggregation completely and it is still possible for the redox couples to penetrate through the gaps in or between the rigid benzene rings. Efforts to add long alkyl chains in the middle of the starburst type (triaryl-truexene) dyes to form cone shape sensitizers have successfully form compact blocking layers on the $\mathrm{TiO}_{2}$ surface that suppressed the approach of the $I_{3}^{-}$ions to the $\mathrm{TiO}_{2}$ particles, retarding charge recombination [35].

Table 4 shows large LUMO-HOMO energy gaps within all the compounds other than A7. Due to this, electrons will find it challenging to get excited, thus inducing large charge recombinations, resulting in low cell efficiencies. Minimal charge recombinations occurs if the HOMO is close to $E_{C B e}$ (Figure 7), since the $I^{-} / I_{3}^{-}$electrolyte has a redox potential of $-4.6 \mathrm{eV}$. A negative value for the charge recombination in $\mathbf{A 7}$, indicates that when electrons are regenerated, they do not reach the HOMO of the dye. This can be circumvented by replacing the $I^{-} / I_{3}^{-}$electrolyte with $\mathrm{Co}^{\mathrm{III} / \mathrm{II}}$ electrolyte, since the latter has a redox potential of $-5.0 \mathrm{eV}$ [4]. Other than A8, low levels of co-planarity are observed between donor groups and $\pi$-spacer groups, suggesting no smooth transfer of electrons within these fragments occurred. The smoothest transfer of electrons between $\pi$-spacer groups and acceptor groups occurred in A3. Other than A5, it is highly unlikely that dye aggregation from intermolecular interactions between molecules can occur due to large dihedral angles between their donor and acceptor groups. Due to this, most compounds have the potential to serve as dyes that can inject photo electrons into the conduction band edge of $\mathrm{TiO}_{2}$. Negative intra-fragment-charge-transfer (IFCT) for D- $\pi-\mathrm{A}$ in A3 and A6 means that their acceptor groups does not contain any photo electrons that they can inject into the conduction band edge of $\mathrm{TiO}_{2}$. As we have already established that $\mathbf{A 3}$ might not serve as a DSSC, this gives a more plausible reason for its ineffectiveness. The low $\mu$ probably caused A6 to prevent charge being transferred to the acceptor segment. This low $\mu$ probably results from the distance of charge transfer upon excitation [20]. The high IFCT in A4 means that its acceptor fragment contains a large amount of photo electrons that it can inject into the conduction band edge of $\mathrm{TiO}_{2}$. 
Table 4. Photophysicochemical parameters of the dyes before injection into the conduction band edge of $\mathrm{TiO}_{2}$

$\begin{array}{lllll}\underline{\text { HOMO }} & \underline{\text { LUMO }} & \underline{\text { HOMO-LUMO }} & \underline{\Delta G_{r e c}^{0}(\mathrm{eV})} & \underline{\text { IFCT }} \\ \underline{(\mathrm{eV})} & \underline{(\mathrm{eV})} & \underline{(\mathrm{eV})} & \underline{(\mathrm{D}-\pi-\mathrm{A}}\end{array}$

\begin{tabular}{|c|c|c|c|c|c|c|c|c|}
\hline A1 & -7.37 & -2.25 & 5.11 & 2.77 & 0.246 & 34.9 & 22.2 & 69.2 \\
\hline A2 & -6.77 & -1.77 & 5.0 & 2.17 & 0.298 & 55.9 & 52.4 & 49.0 \\
\hline \multirow[t]{2}{*}{ A3 } & $-6.25^{\mathrm{a}}$ & $-2.21^{\mathrm{a}}$ & $4.04^{\mathrm{a}}$ & $1.65^{\mathrm{a}}$ & -0.00190 & 33.9 & 10.0 & 37.6 \\
\hline & $-6.75^{b}$ & $-2.21^{b}$ & $4.54^{\mathrm{b}}$ & $2.15^{\mathrm{b}}$ & & & & \\
\hline A4 & -5.91 & -1.95 & 3.96 & 1.31 & 0.408 & 68.0 & 25.6 & 83.4 \\
\hline A5 & -6.14 & -1.81 & 4.34 & 1.54 & 0.133 & 75.6 & 82.9 & 11.9 \\
\hline A6 & -6.85 & -1.81 & 5.04 & 2.25 & -0.0179 & 36.7 & 89.3 & 89.7 \\
\hline A7 & -4.41 & -1.76 & 2.65 & -0.19 & 0.0411 & 68.4 & 54.4 & 75.9 \\
\hline \multirow[t]{2}{*}{ A8 } & $-6.27^{a}$ & $-1.73^{a}$ & $4.54^{\mathrm{a}}$ & $1.67^{\mathrm{a}}$ & 0.00196 & 9.87 & 52.6 & 34.8 \\
\hline & $-6.27^{b}$ & $-2.94^{b}$ & $3.32^{\mathrm{b}}$ & $1.67^{b}$ & & & & \\
\hline
\end{tabular}

$\mathrm{a}=\alpha$

$\mathrm{b}=\beta$

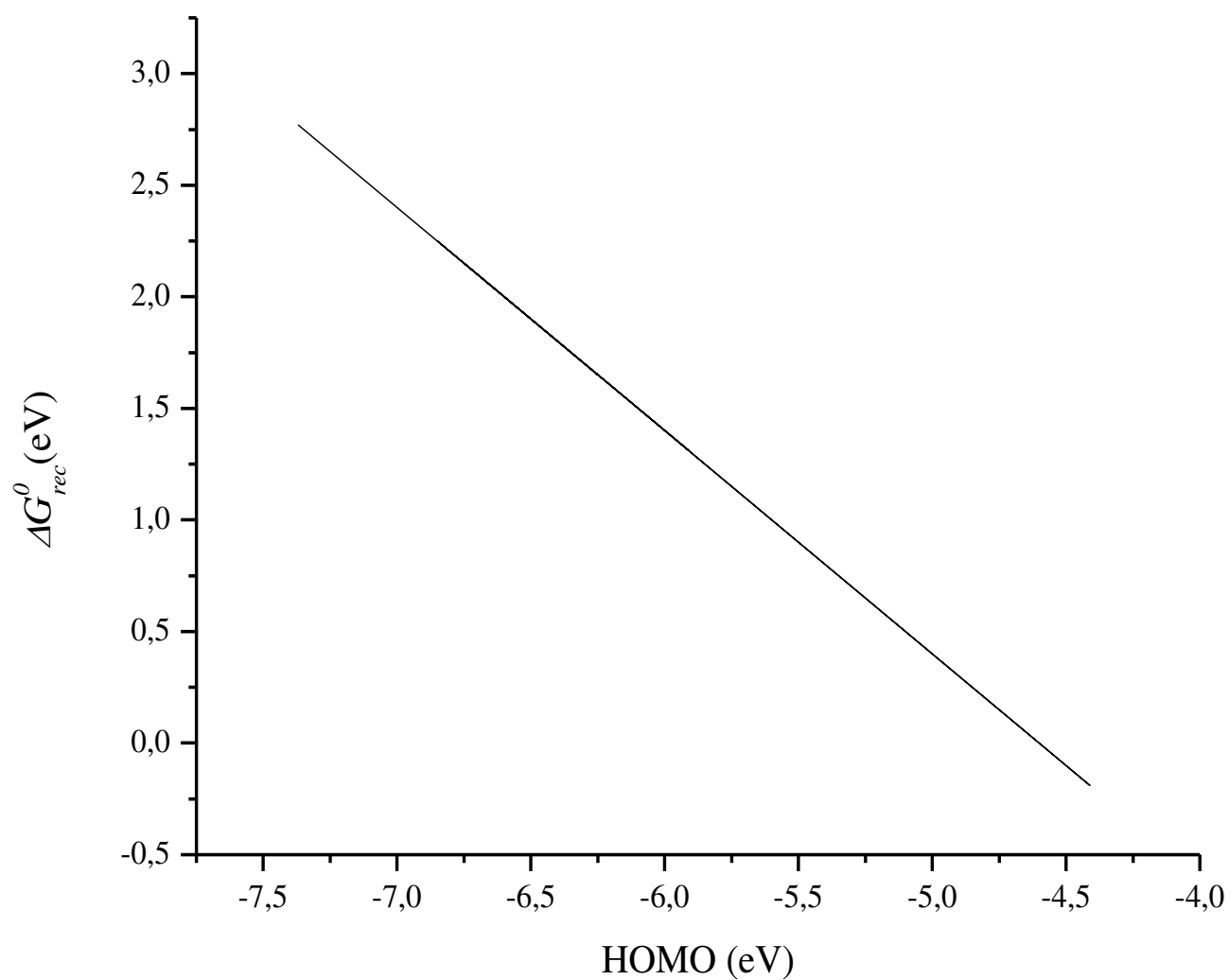

Figure 7. Charge recombinations for the ground state redox potentials of the dyes 
The nature of solvent media, the incident photon energy and its pulse width are some of the factors that contributes to the emission of photons as fluorescence by molecules from the first excited state $\left(S_{1}\right)$ to the ground state $\left(S_{0}\right)$. In our case, we can ignore these factors in the interpretation of the results since our study was carried out in silico. Thus, our model only considers the calculated excited state properties that depends on the geometrical configurations of the studied molecules. Various excited state processes such as internal conversion, vibrational relaxation, intersystem crossing, and fluorescence emission play a role in deactivating the molecule's excited state energy. Possibilities exist for both highly absorbing and poorly absorbing molecules to fluoresce greatly if deactivation by fluorescence is favoured. The presence of the other processes quench fluorescence whether the molecule is highly or poorly absorbing.

TD-DFT calculated emission spectra for $\lambda_{\max }$ and $\varepsilon_{\mathrm{em}}$ are depicted in Table 5. A1 and $\mathbf{A} 2$ absorbs just below the spectral range. Other than A5 and A7, no Stokes' shifts in wavelengths occurred. The latter in particular showed a very large Stokes' shift. However, its emitted wavelength lies outside the target spectral range $400-800 \mathrm{~nm}$, and it also showed a very poor emission spectrum. Although the emitted $\lambda_{\max }$ shifted to the visible region in $\mathbf{A 5}$, it also displayed a very poor emission spectrum. No emission spectra were obtained for A3 and A8. Earlier, it was found that $\mathbf{A 4}$ contains a large number of photoelectrons on its accepter segment that it can inject, however, its poor $\varepsilon_{\mathrm{em}}$ suggest otherwise.
Table 5. Emitted wavelengths and emission coefficients for dyes upon fluorescence

$\begin{array}{lll} & \lambda_{\max }(\mathbf{n m}) & \text { Eem } \\ \text { A1 } & 388.65 & 34441.07 \\ \text { A2 } & 389.67 & 36410.62 \\ \text { A3 } & 0 & 0 \\ \text { A4 } & 474.13 & 319.50 \\ \text { A5 } & 400.02 & 392.29 \\ \text { A6 } & 341.84 & 19829.09 \\ \text { A7 } & 2414.26 & 105.15 \\ \text { A8 } & 0 & 0\end{array}$

Large differences are clearly observed in (c), (d) and (f) in Figure 8. As $\mathbf{A 3}$ and $\mathbf{A 8}$ do not display emission spectra, no comparison between absorption and emission spectra could be drawn for them.

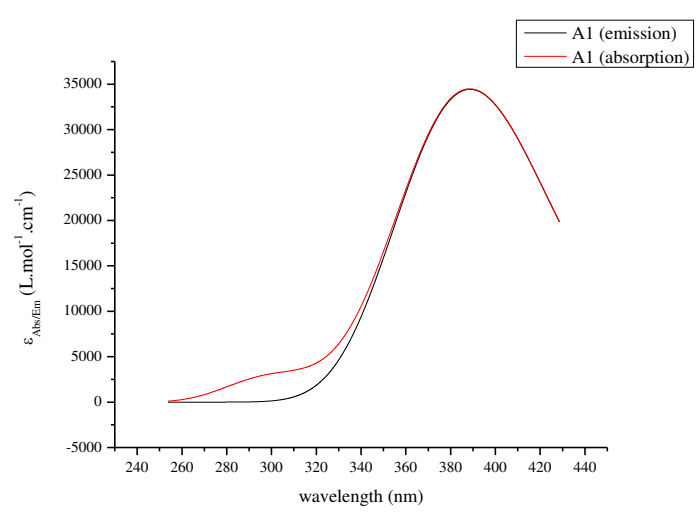

(a)

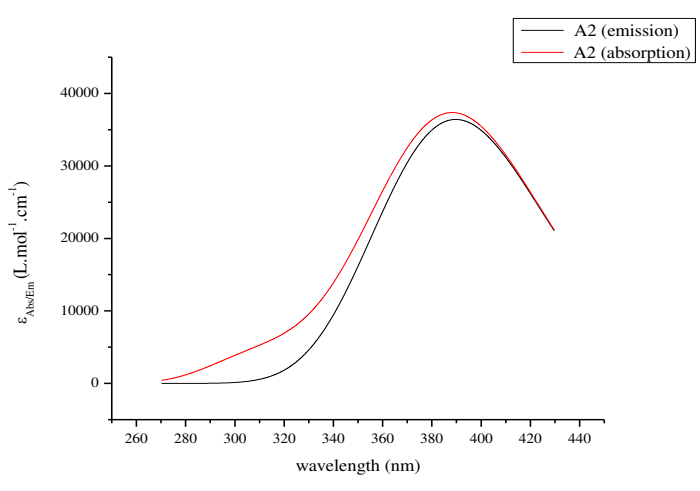

(b) 


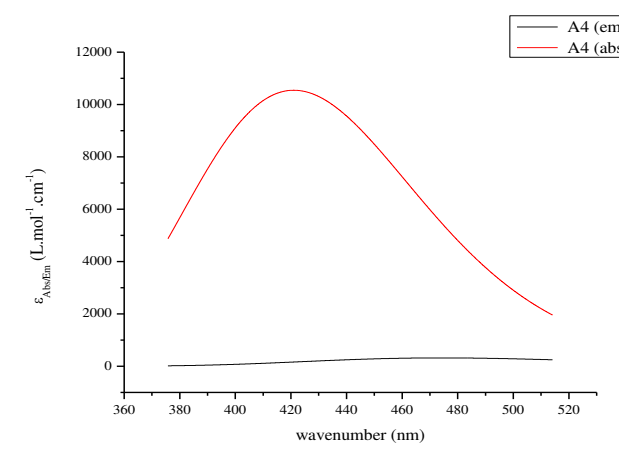

(c)

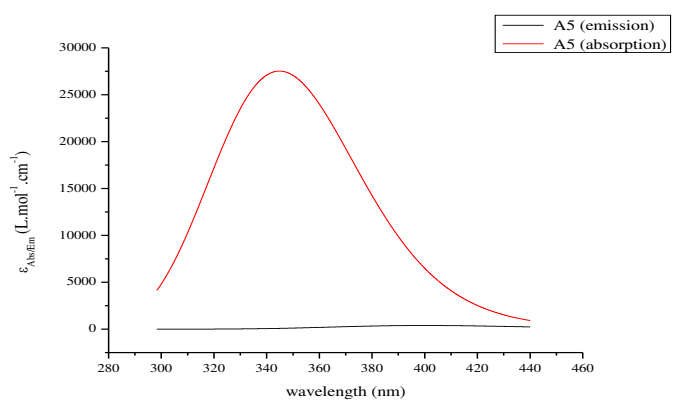

(d)

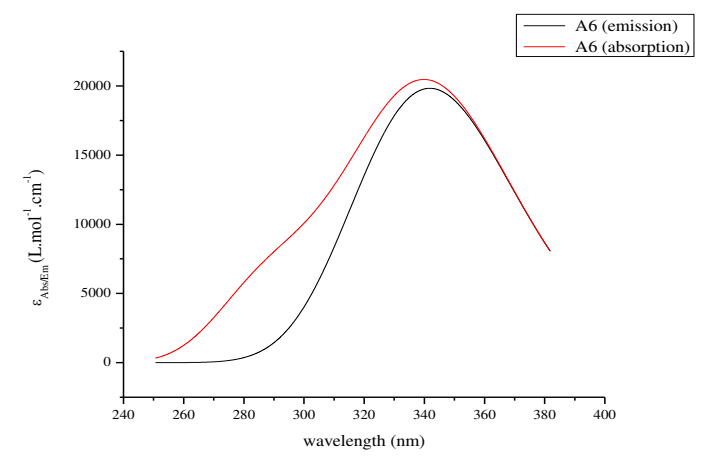

(e)

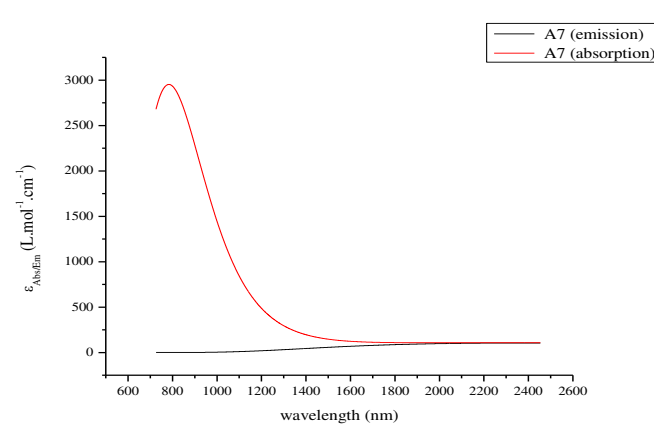

(f)

Figure 8. Absorption and emission spectra of potential dyes
Figure 9 reveals an explanation why some molecules hold DSSC properties and others not. For any molecule to be considered a DSSC, its HOMO must be localized over the donor groups, while its LUMO should be delocalized over its acceptor groups. Thus, it is expected that electrons be localized over starburst donor moieties and delocalized over cyanoacrylic acid acceptor moieties. In the case of A1, both HOMO and LUMO are localized over the triazole ring, one of the phenyl rings and acceptor group. This could be due to the absence of donor moieties. When adding the donor moiety to produce A2, then the $\pi$ electrons are indeed localized over the HOMO and delocalized over the LUMO. As A3 contains $\alpha$ and $\beta$ HOMO and LUMO, in the absence of strong donor groups, its $\pi$-electrons are localized over the triazole ring, while its $\pi$-electrons are then delocalized over only one of its three acceptor groups. None of the $\pi$-electrons are localized over the two donor groups in $\mathbf{A 4}$, although they are delocalized over the acceptor group. Localization of $\pi$-electrons occurred in only one of the two donor groups in $\mathbf{A 5}$ and delocalized to the acceptor group. A similar phenomenon occurred in A6. The $\pi$ electrons were localized over the $\pi$-spacer group rather than the donor group in A7, although they were delocalized to the acceptor group. 


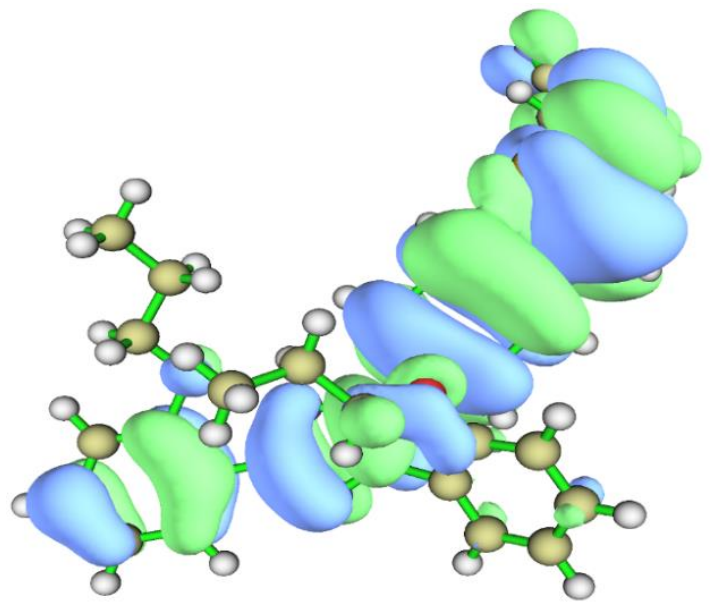

HOMO of A1

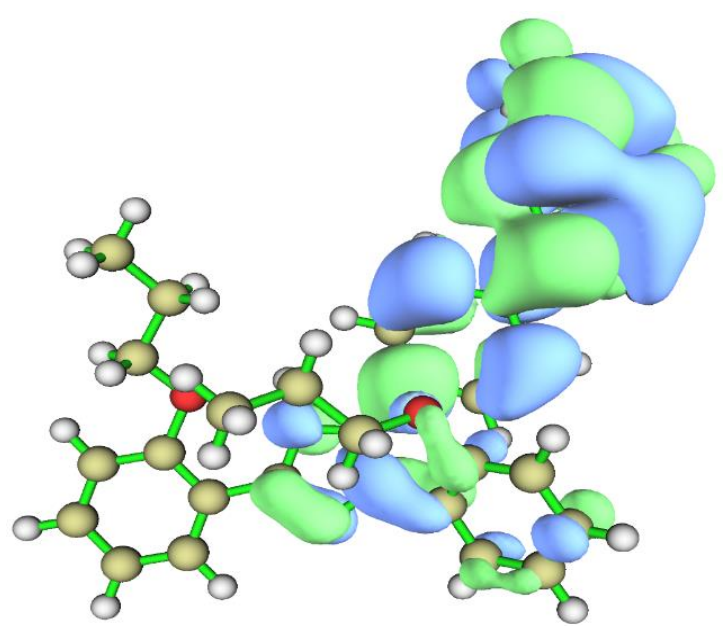

LUMO of A1

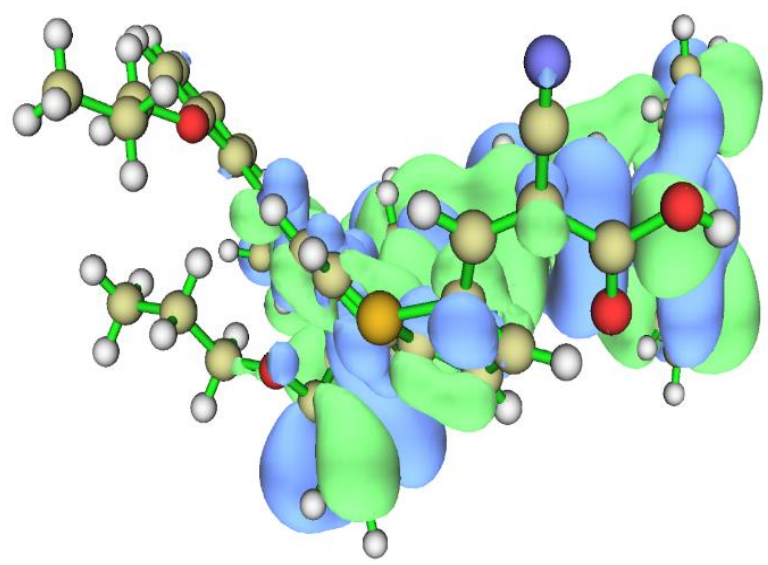

HOMO of A2

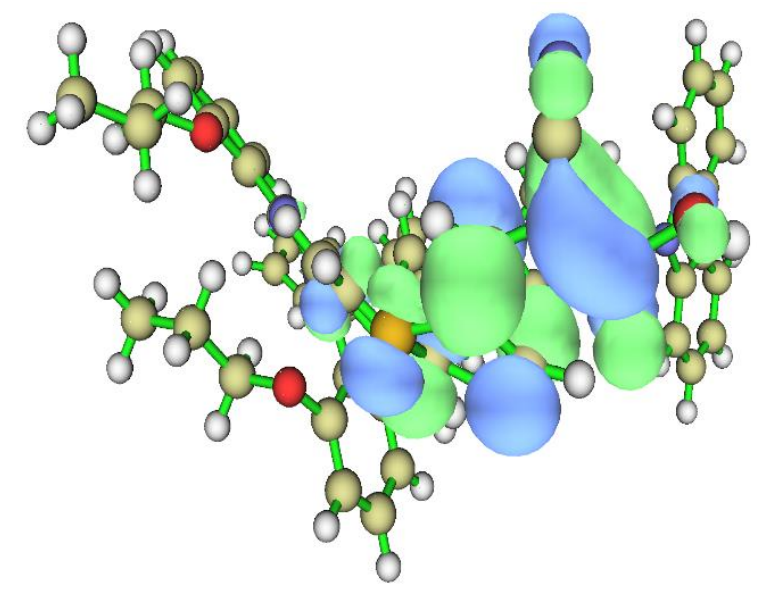

LUMO of A2

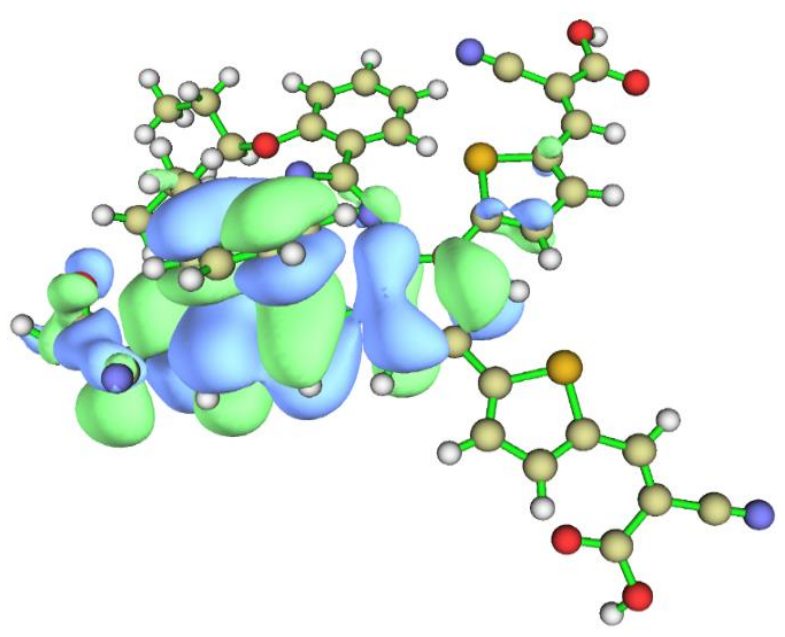

Alpha-HOMO of A3

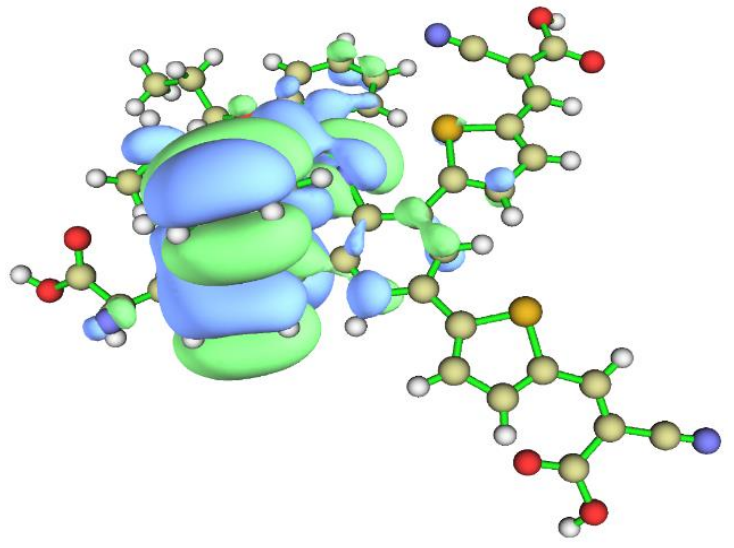

Beta-HOMO of A3 


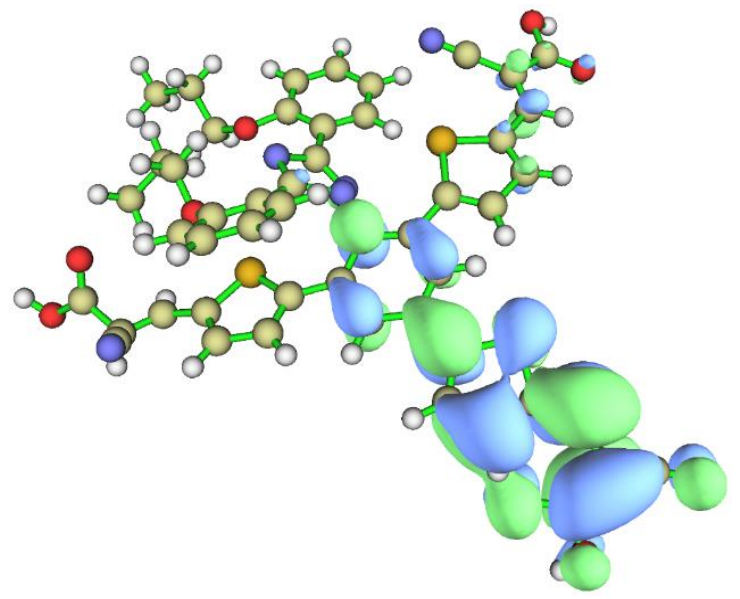

Alpha-LUMO of A3

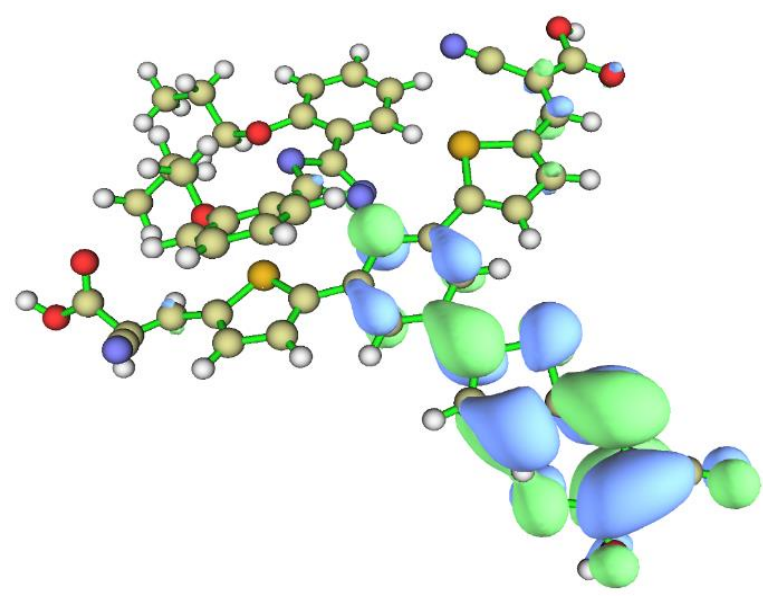

Beta-LUMO of $\mathbf{A 3}$

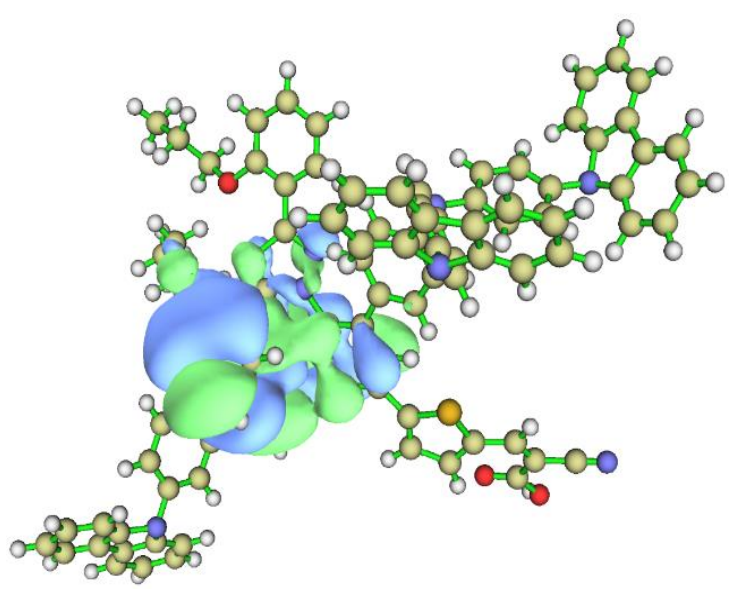

HOMO of A4

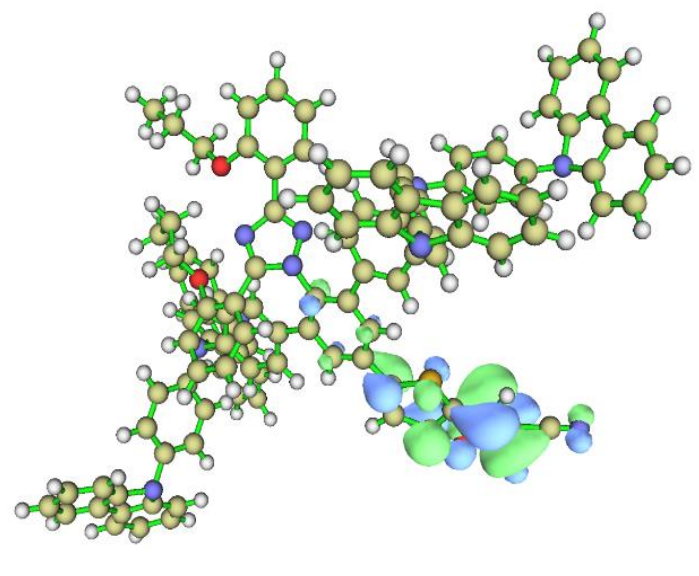

LUMO of A4

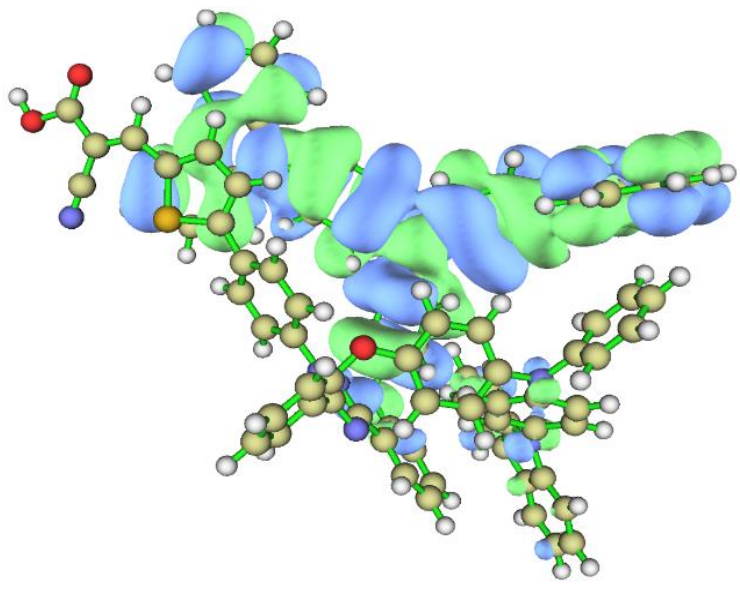

HOMO of A5

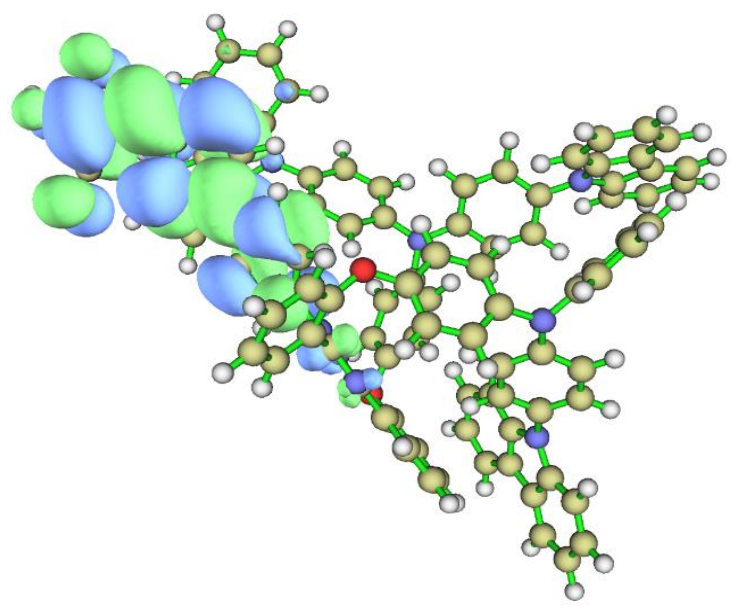

LUMO of A5 


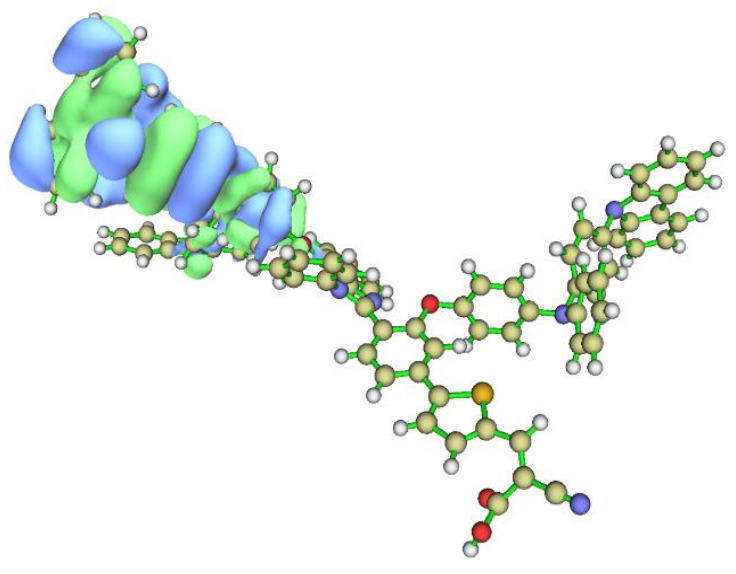

HOMO of A6
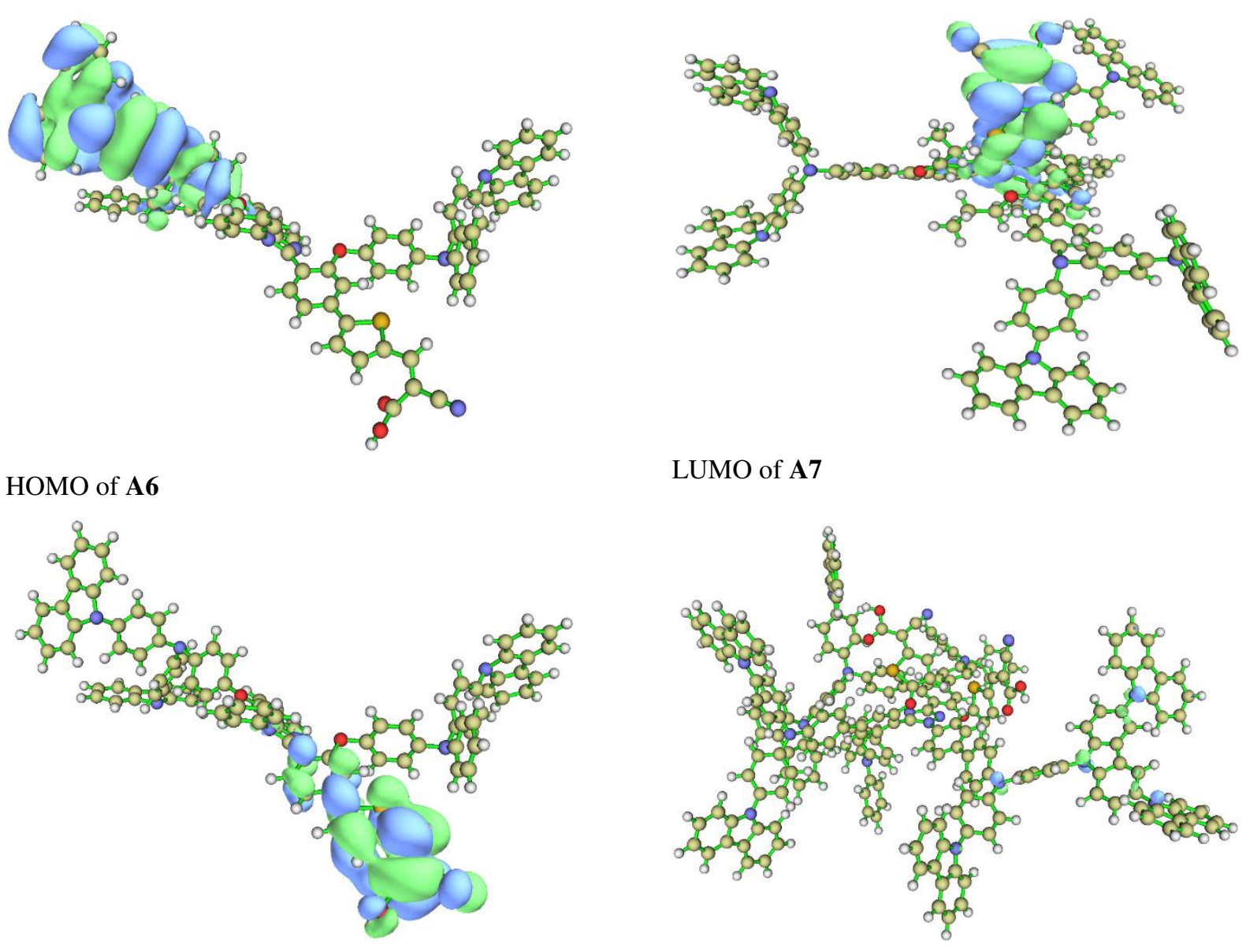

LUMO of A6

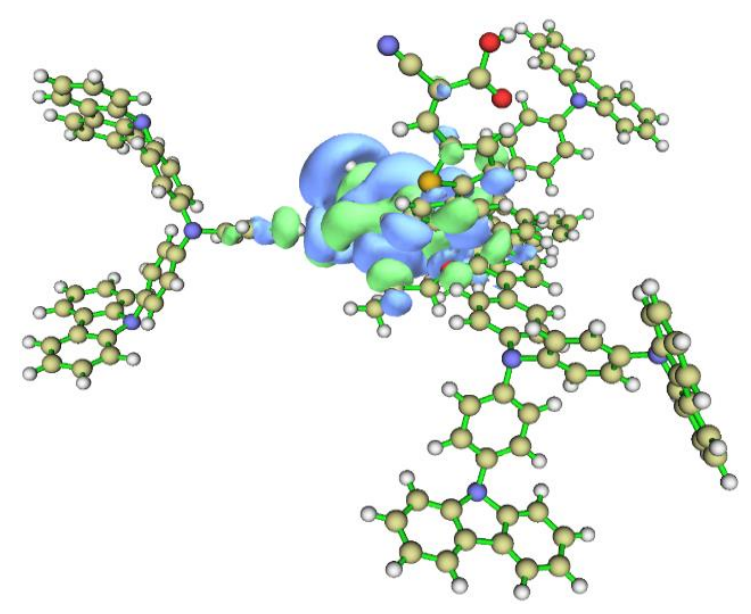

HOMO of A7

LUMO of A7

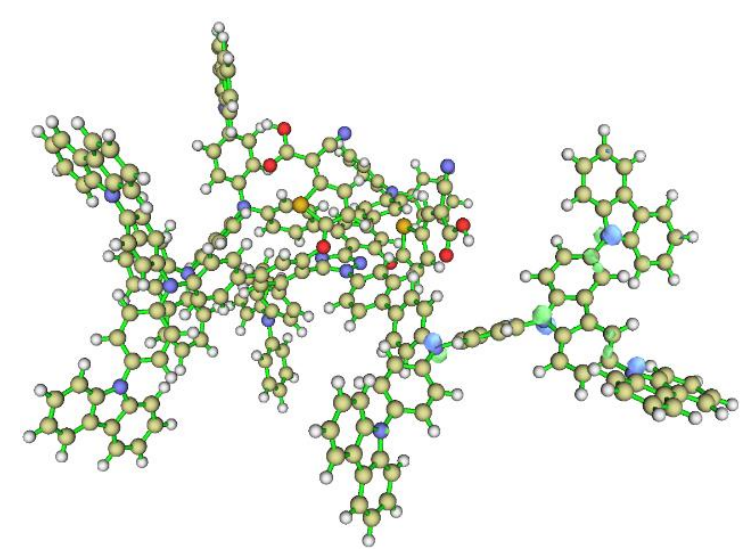

Alpha-HOMO of $\mathbf{A 8}$

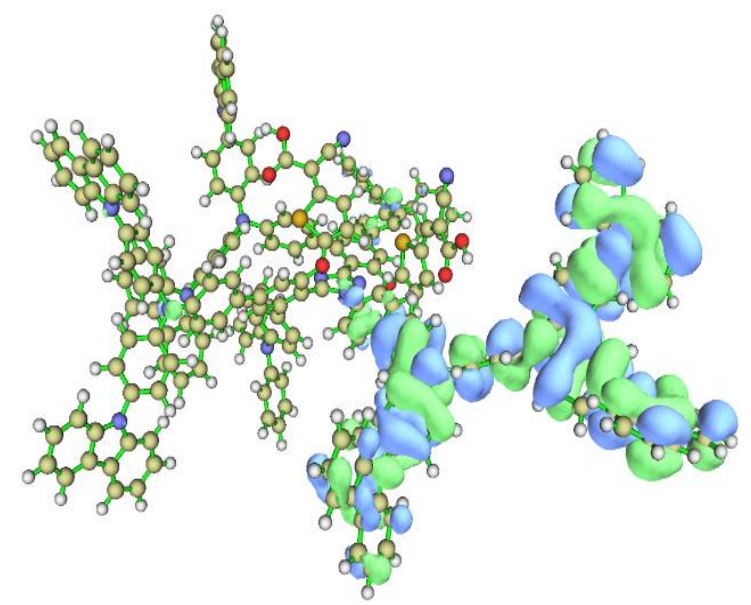

Beta-HOMO of $\mathbf{A 8}$ 


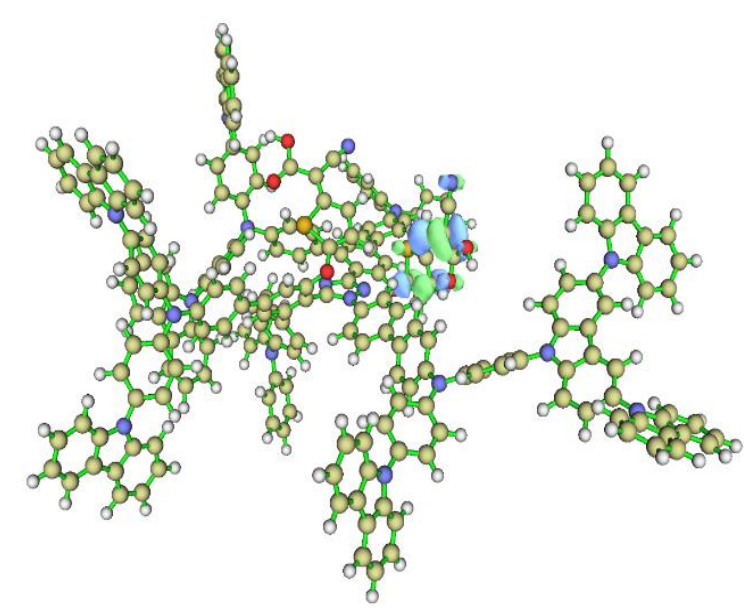

Alpha-LUMO of $\mathbf{A 8}$

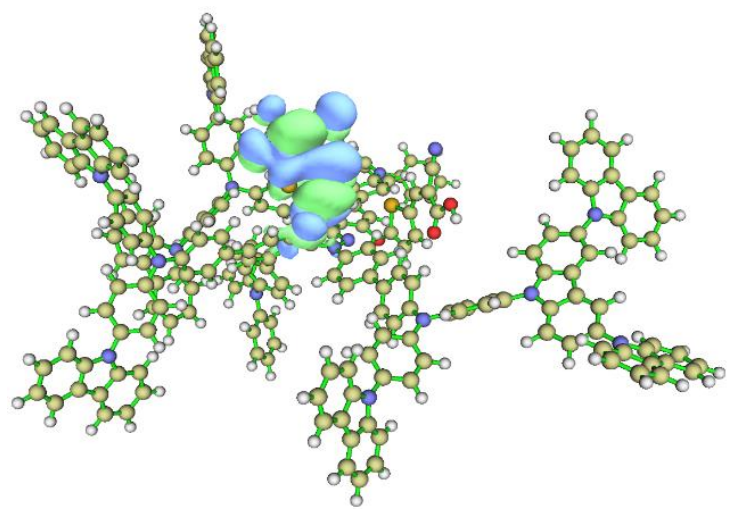

Beta-LUMO of $\mathbf{A 8}$

Figure 9: Highest occupied molecular orbitals and lowest unoccupied molecular orbitals of molecules

\subsubsection{Photovoltaic properties}

The estimated molecular radii $\left(r_{d y e}\right)$ and the diffusion coefficients $\left(D_{\pi}\right)$ in Table 6 are consistent with literature values [32], verifying valid assumptions and accurate methods of calculations. An inversely proportional relationship between $D_{\pi}$ and the size of the dye (Figure 6) reveals its expected dependence on the molecular dye radii [32]. The $\Delta G_{i n j}$ values favours the electron injection process into the $E_{C B}$ edge, which is also suggested by the $\delta_{\mathrm{p}}$ values. From Table 6, a relationship between $\Delta G_{i n j}$ and $\delta_{p}$ can be established where the sign between the latter and the former alternates. At the interface between the acceptor fragment and the conduction band edge of $\mathrm{TiO}_{2}$, the charge collection efficiency $\left(\eta_{\mathrm{c}}\right)$ can determine the probability of the availability of an electron before injection. It is expected that more available electrons should produce a higher incidentphoto-conversion-efficiency (IPCE), which will subsequently cause a greater efficiency when being used as a DSSC. However, as Table 6 indicates, this is not the case since LHE and $\Phi_{i n j}$ also play a role in IPCE. From this table, it is observed that $\mathbf{A} 2$ possess the highest IPCE value and thus holds the best properties as a potential DSSC. Because A3 and A8 do not serve as DSSCs, no IPCE are observed within these compounds although they do display charge collection efficiencies as well as free injection energies. 
Table 6. Photovoltaic parameters of the dyes when injecting into the conduction band edge of $\mathrm{TiO}_{2}$

\begin{tabular}{|c|c|c|c|c|c|c|c|}
\hline & $\underline{D}_{\underline{\pi}} \underline{\left(1 \times 10^{-11} \mathrm{~m}^{2} \cdot \mathrm{s}^{-1}\right)}$ & $\underline{r}_{\text {dye }}(\mathrm{nm})$ & $\underline{\Phi}_{f}$ & $\underline{\delta_{p}}$ & $\underline{n}_{\underline{c}}\left(1 \times 10^{-12}\right)$ & $\underline{\Delta G} \underline{i n j}(\mathrm{eV})$ & $\underline{\operatorname{IPCE}\left(1 \times 10^{-15}\right)}$ \\
\hline A1 & 7.91 & 1.38 & 0.999 & -7.74 & 1.32 & 1.96 & 1130 \\
\hline A2 & 6.35 & 1.72 & 0.975 & -5.26 & 2.29 & 2.44 & 1950 \\
\hline \multirow[t]{2}{*}{ A3 } & 6.78 & 1.61 & 0 & $-5.70^{a}$ & $2.04^{\mathrm{a}}$ & $2.0^{\mathrm{a}}$ & 0 \\
\hline & & & & $-5.70^{b}$ & $2.09^{b}$ & $2.0^{\mathrm{b}}$ & \\
\hline A4 & 5.54 & 1.97 & 0.0303 & -5.44 & 1.87 & 2.26 & 1.020 \\
\hline A5 & 5.63 & 1.94 & 0.0143 & -5.30 & 2.00 & 2.40 & 187.0 \\
\hline A6 & 5.63 & 1.94 & 0.969 & -5.30 & 2.00 & 2.40 & 1310 \\
\hline A7 & 5.03 & 2.17 & 0.0356 & -5.26 & 1.82 & 2.44 & 5.660 \\
\hline \multirow[t]{2}{*}{ A8 } & 4.96 & 2.20 & 0 & $-5.22^{\mathrm{a}}$ & $1.82^{\mathrm{a}}$ & $2.48^{\mathrm{a}}$ & 0 \\
\hline & & & & $-6.43^{b}$ & $1.20^{\mathrm{b}}$ & $1.27^{\mathrm{b}}$ & \\
\hline
\end{tabular}

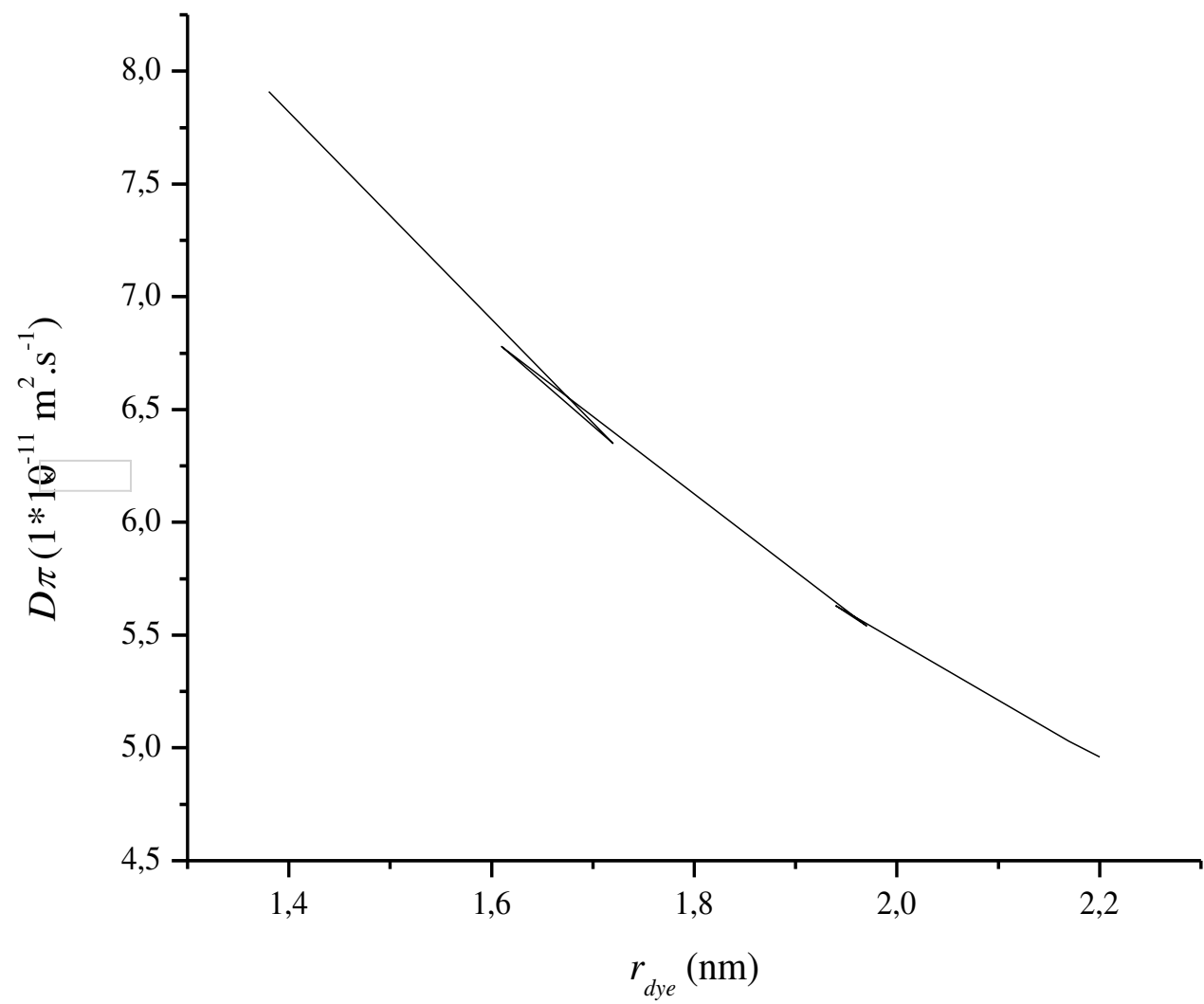

Figure 9. Relationship between the diffusion constant $\left(D_{\pi}\right)$ and the size of the dye 


\section{Conclusion}

Highly conjugated novel metal-free 1,2,4-triazole compounds were evaluated for applications in dye sensitized solar cells (DSSCs). A density functional theory (DFT) method was used to study their photophysicochemical and photovoltaic properties. To generate electronic absorption and emission spectra, time-dependent density functional theory (TD-DFT) calculations were performed. From these calculations, the highest occupied molecular orbital (HOMO), the lowest unoccupied molecular orbital (LUMO) with respect to the $\mathrm{TiO}_{2}$ conduction band $\left(\delta_{p}\right)$, pi-electron diffusion coefficients $\left(D_{\pi}\right)$, intrafragment-charge-transfer (IFCT), and molar absorptivity $(\varepsilon)$ and emission $\left(\varepsilon_{e m}\right)$ coefficients at maximum absorption and emission wavelengths were determined. Through these parameters, the fluorescence emission $\left(\Phi_{f}\right)$, free energy injection $\left(\Delta G_{i n j}\right)$, charge recombinations $\left(\Delta G_{\text {rec }}^{\mathbf{0}}\right)$ and charge collection $\left(\eta_{c}\right)$ efficiencies were obtained. The dyes' incident photon conversion efficiency (IPCE) was then obtained using $\Phi_{f}$ and $\eta_{c}$ values. All these calculated properties were then used to predict the suitability of each molecule as an organic dye in DSSCs. The overall results showed that $\mathbf{A 2}$ is the most suitable dye, although it absorbs slightly below the visible region, while $\mathbf{A 3}$ and $\mathbf{A 8}$ showed no dye characteristics. It is highly unlikely that the other molecules will also serve as dyes due to low $\varepsilon_{e m}$, low interfacial dipole moments $(\mu)$ and negative intrafragment-charge-transfer (IFCT) values. Although this method is useful to predict photovoltaic activities of molecules as a guide for designing sensitive dyes without having to do the laborious trial and error method in laboratory synthesis, it cannot predict the efficiencies of the dyes.

\section{Acknowledgements}

The authors would like to acknowledge the center for high performance computing CHPC, South
Africa for providing computational resources for this research project.

\section{Declarations}

Funding Funding acquisition the University of Johannesburg, South Africa.

Conflicts of interests The authors declare no competing interests

Availability of data All data will be available if required

Code Not applicable

Authors' contributions Louis-Charl Coetzee: writing original draft; Adedapo Adeyinka: formal analysis, data curation; Nomampondo Magwa: formal analysis

\section{References}

1. N. Robertson, Angew. Chem. Int. Ed., 2006, 45, 2338-2345

2. A.F. Hina, K. Priya, T.B. Sudakar, K.R. Devabalaji, M. Rekha, K. Rajalakshmi, and C. Shilaja, Int. J. Inn. Res. Sci. Eng. Tech., 2014, 3, 1, 1618-1624

3. Z. Usman, J. Tah, H. Abanda, and C. Nche, Build., 2020, 10, 192, 5, 1-22

4. J.A. Luceno-Sanchez, A.M. Diez-Pascual, and R.P. Capilla, Int. J. Mol. Sci., 2019, 20, 976, 142

5. C.P. lee, C.T. Li, and K.C. Ho, Mat. Tod., 2017, $1-17$

6. R. Chauhan, R. Kushwaha, and L. Bahadur, J. En., 2014, 1-10

7. D. Cao, J. Peng, Y. Hong, X. Fang, L. Wang, and H. Meier, Org. Lett., 2011, 13, 1, 16101613

8. S. Manoharan, S. Anandan, Dyes Pigm., 2014, 
105, 223-231

9. M. Castillo-Valles, J.M. Andres-Casten, J. Garin, J. Orduna, B. Villacampa, S. Franco, and M.J. Blesa, R.S.C. Adv., 2015, 5, 90667-90670

10. L.L. Tan, J.M. Liu, S.Y. Liu, S.Y. Li, L.M. Xiao, Chem. Sus. Chem., 2014, 8, 2

11. L.L. Tan, J.F. Huang, Y. Shen, L.M. Xiao, J.M. Liu, D.B. Kuang, and C.Y. Su, J. Mat. Chem. A, 2014, 2, 8988-8994

12. I.M. Abdellah, A. El-Shafei, J. Photochem. Photobio. A Chem., 2020, 387, 1-10

13. M. Gilbert, and B. Albinsson, Chem. Soc. Rev., $2015,44,4,845-862$

14. J. Tang, J. Hua, W. Wu, J. Li, Z. Jin, Y. Lang, and H. Tian, En. Envir. Sci., 2010, 3, 1736-1745

15. Z. Ning, Q. Zhang, W. Wu, H. Pei, B. Liu, and H. Tian, J. Org. Chem., 2008, 73, 3791-3797

16. P. Naik, M.R. Elmorsy, R. Su, D.D. Babu, A. El-Shafei, A.V. Adhikari, Sol. En., 2017, 153, 600-610

17. P. Naik, R. Su, M.R. Elmorsy, A. El-Shafei, and A.V. Adhikari, Photochem. Photobio. Sci., 2018, 17, 302-314

18. K. Sharma, V. Sharma, and S.S. Sharma, Nan. Res. Lett., 2018, 13, 381, 1-46

19. X. Zarate, S. Schott-Verdugo, A. RodriguesSerrano, and E. Schott, J. Phy. Chem. A, 2016, 120, 1613-1624

20. N. Kungwan, P. Khangpracha, S. Namuangruk, J. Meeprasert, C. Chitpakalee, S. Jungsuttiwong, Theor. Chem. Acc., 2014, 133, 1523

21. A.R.K. Selvaraj, and S. Hayase, J. Mol. Model., 2012, 18, 2099-2104

22. S. Namuangruk, J. Meeprasert, S. Jungsuttiwong, V. Promarak, N. Kungwan, Theor. Chem. Acc., 2014, 133, 1534

23. X. Zarate, F. Claveria-Cadiz, D. Arias-Olivares, A. Rodriguez-Serrano, N. Inostroza, and E.
Schott, Phys. Chem. Chem. Phys., 2016, 1-13

24. M. Raftani, T. Abraham, N. Bennani, and M. Bouchrine, Res. Chem., 2020, 2, 1-12

25. R.M. El-Shishtawy, A.M. Asiri, S.G. Aziz, S.A.K. Elroby, J. Mol. Model., 2014, 20, 22412249

26. G. de Miguel, M. Wielopolski, D.I. Schuster, M.A. Fazio, O.P. Lee, C.K. Haley, A.L. Ortiz, L. Echegoyen, T. Clarke, and D.M. Guldi, J. Am. Chem. Soc., 2011, 133, 13036-13054

27. P. Kautny, C. Zhao, T. Kader, B. Stager, E. Horkel, J. Chen, D. Ma, J. Frohlich, and D. Lumpi, R.S.C. Adv., 2017, 7, 20, 12150-12160

28. D. Liu, D. Li, M. Wang, and W. Li, J. mat. Chem. C, 2016, 1-29

29. M. Romain, D. Tondelier, O. Jeannin, B. Geffroy, J. Rault-Berthelot, and C. Poriel, J. Mat. Chem. C, 2015, 3, 9701-9714

30. Y. Tao, Q. Wang, L. Ao, C. Zhang, C. Yang, J. Qin, and D. Ma, J. Phys. Chem. C, 2010, 114, 1, 601-609

31. M.J. Friesh, G. Truks, H. Schlegel, G. Scuseria, M. Robb, J. Cheeseman, G. Scalmani,

V. Barone, B. Mennucci, G. Pettersson: Gaussian 09, Revision D.01, Gaussian Inc.;

Wallingford, CT, 2009

32. K. Sanusi, N.O. Fatomi, A.O. Borisade, Y. Yilmaz, U. Ceylan, and A. Fashina, Chem. Phys. Lett., 2019, 1-7

33. J. Zhang, Y.H. Kan, H.B. Li, Y. Geng, Y. Wu, Z.M. Su, Dyes Pigm., 2012, 95, 313

34. A.D. Becke, J. Chem. Phys., 1993, 98, 5648

35. Z. Ning, Q. Zhang, H. Pei, J. Luan, C. Lu, Y. Cui, and H. Tian, J. Phys. Chem. C, 2009, 113, 10307-10313

36. J.D. Kubicki, and H.D. Watts, Min., 2019, 9, 41, $1-20$ 


\section{Supplementary Files}

This is a list of supplementary files associated with this preprint. Click to download.

- 124decoratedtriazoles.zip

- DSSCESIver3.docx

- HighlightsASedited.docx

- PermissionRequest.png

- PermissionfromAuthor.png

- declarationofcompetinginterests5.docx 